\title{
Involvement of TIMP-1 in PECAM-1-mediated tumor dissemination
}

\author{
VALSAMMA ABRAHAM ${ }^{1,2}$, GAOYUAN CAO $^{3}$, ANDREW PARAMBATH $^{1}$, FAREEDAH LAWAL $^{1}$, \\ CHAKKRAPONG HANDUMRONGKUL ${ }^{4}$, ROBERT DEBS ${ }^{4}$ and HORACE M. DELISSER ${ }^{1,2}$
}

\author{
${ }^{1}$ Pulmonary, Allergy and Critical Care Division, Department of Medicine, Perelman School of Medicine, \\ University of Pennsylvania; ${ }^{2}$ Department of Medicine, Corporal Michael J. Crescenz Veterans Affairs Medical Center, \\ Philadelphia, PA 19104; ${ }^{3}$ Rutgers Institute for Translational Medicine and Science, Child Health Institute of New Jersey, \\ Rutgers University, New Brunswick, NJ 08901; ${ }^{4}$ California Pacific Medical Center Research Institute, \\ San Francisco, CA 94107, USA
}

Received December 18, 2017; Accepted May 17, 2018

DOI: $10.3892 /$ ijo.2018.4422

\begin{abstract}
Platelet endothelial cell adhesion molecule-1 (PECAM-1) is expressed on the vascular endothelium and has been implicated in the late progression of metastatic tumors. The activity of PECAM-1 appears to be mediated by modulation of the tumor microenvironment (TME) and promotion of tumor cell proliferation, rather than through the stimulation of tumor angiogenesis. The present study aimed to extend those initial findings by indicating that the presence of functional PECAM-1 on the endothelium promotes a proliferative tumor cell phenotype in vivo, as well as in tumor cell (B16-F10 melanoma and 4T1 breast cancer cell lines) co-culture assays with mouse endothelial cells (ECs) or a surrogate EC line (REN-MP). The pro-proliferative effects were mediated by soluble endothelial-derived factors that were dependent on PECAM-1 homophilic ligand interactions, but which were independent of PECAM-1-dependent signaling. Further analysis of the conditioned media obtained from tumor/EC and tumor/REN-MP co-cultures identified TIMP metallopeptidase inhibitor-1 (TIMP-1) as a PECAM-1-regulated factor, the targeting of which in the tumor cell/REN-MP system inhibited tumor cell proliferation. In addition, TIMP-1 expression was decreased in metastatic tumors from the lungs of PECAM-1-null mice, thus providing evidence of the in vivo significance of co-culture studies. Taken together, these studies indicated that endothelial PECAM-1, through PECAM-1-dependent homophilic binding interactions, may induce release of TIMP-1 from the endothelium into the TME, thus leading to increased tumor cell proliferation.
\end{abstract}

Correspondence to: Dr Horace M. DeLisser, Pulmonary, Allergy and Critical Care Division, Department of Medicine, Perelman School of Medicine, Room 644, Jordan Medical Education Center, 6th Floor, Building 421, 3400 Civic Center Blvd, Philadelphia, PA 19104, USA E-mail: delisser@pennmedicine.upenn.edu

Key words: PECAM-1, TIMP-1, endothelial cells, tumor metastasis

\section{Introduction}

Tumors consist of not only malignant cells, but also of a number of non-malignant cells, including endothelial cells (ECs), pericytes, cancer-associated fibroblasts, and immune and inflammatory cells, which are recruited and/or activated by tumor cells (1-6). Crosstalk exists between malignant and non-malignant cells, and is mediated by direct cell-cell interactions and/or by soluble mediators. Stromal cells are a critical element of the tumor microenvironment (TME), releasing various factors that directly stimulate tumor growth and spread, and/or remodel the extracellular matrix (ECM) to ensure it is permissive of tumor growth. In addition, leakiness of the tumor vasculature provides additional serum-derived factors that contribute to further remodeling of the $\operatorname{ECM}(6,7)$. However, the presence of interstitial hypertension, as well as tissue hypoxia and acidosis, means there are physical and biochemical barriers in the TME that must be overcome if the tumor is to grow and spread (7). Furthermore, it is now recognized that the TME for core primary tumors, invasive tumors and metastatic tumors are distinct from each other $(7,8)$. Although the role of the TME in the growth and spread of primary tumors has been the subject of intense investigation, comparatively less attention has been given to the role that the TME, particularly its stromal cell constituents, might serve in regulating the progression of metastatic tumor foci $(4,5)$.

Platelet endothelial cell adhesion molecule-1 (PECAM-1) is a vascular-associated molecule of the immunoglobulin (Ig) superfamily, which is expressed on platelets, leukocytes and ECs, where it is enriched at intercellular junctions (9-11). With respect to its structure, the extracellular domain is composed of six Ig-like domains (12), with distinct residues in Ig-like domain 1 (12-14) and Ig-like domains 2 and 3 (15) mediating homophilic and heparin/glycosaminoglycan (GAG)-dependent heterophilic binding, respectively. Factors that promote homophilic over GAG-dependent heterophilic adhesion include a high surface density, antibody-mediated engagement of the membrane proximal Ig-like domain 6 , and the absence of sequences from the cytoplasmic domain coded by exon 14 of 
the PECAM-1 gene (16,17). Additionally, homophilic adhesion is dependent on the glycosylation state of PECAM-1 $(18,19)$. In terms of intracellular signaling, phosphorylation of tyrosines 663 and 686 in the cytoplasmic domain of PECAM-1 creates docking sites for the binding and activation of several cytosolic signaling molecules containing Src homology 2 domains (20-24).

The involvement of PECAM-1 in numerous physiological processes, including leukocyte emigration (14,25-27), T-cell activation $(28,29)$, platelet aggregation $(30,31)$, angiogenesis (32-35) and protection of the endothelium from endotoxic stress $(36,37)$, has previously been reported. PECAM-1 has also been implicated in advanced metastatic tumor progression (38). In this previous study regarding tumor metastasis (38), anti-PECAM-1 antibody was reported to inhibit the late stage metastatic progression of various tumors, but did not block tumor-platelet and tumor-endothelial interactions, which are events associated with the initial establishment of metastatic tumor foci. Notably, the antibody employed binds ECs, but does not bind to tumors or affect tumor cell proliferation. Consistent with these data, it was revealed that in PECAM-1-null mice, while the initial establishment of B16-F10 tumor metastases is not suppressed, the progression of sub-clinical tumor foci to larger, clinically evident lesions is inhibited. Reciprocal (wild-type vs. PECAM-1-null mice) bone marrow chimeric mice confirmed that the pro-metastatic effects of the molecule are mediated by endothelial, and not leukocyte or platelet PECAM-1. Furthermore, while tumor angiogenic and apoptotic rates are comparable in antibody-treated and control animals, tumor mitotic rates are significantly reduced by treatment with the anti-PECAM-1 antibody. There are also no alterations in the pattern or number of leukocytes within the tumors. Since the anti-PECAM-1 antibody used in these studies does not bind to tumor cells or inhibit their proliferation, these data indicate that in vivo, the presence of functionally active PECAM-1 on the vascular endothelium promotes a proliferative tumor phenotype that promotes advanced metastatic tumor progression (38).

TIMP metallopeptidase inhibitor-1 (TIMP-1) is a member of a family of broad-spectrum endogenous inhibitors of matrix metallopeptidases (MMPs), which act to block MMP proteolytic activity by forming 1:1 non-covalent complexes with the metallopeptidase $(39,40)$. Due to the activity of MMPs in ECM remodeling, growth factor availability and in cell surface receptor expression, TIMPs, through their modulation of MMPs, are involved in numerous physiological (wound healing) and pathological (tumor growth and invasion) processes (40). There is, however, increasing evidence to suggest that TIMP-1 is also able to promote cell proliferation and survival, including that of tumor cells, independent of MMP inhibition (41-43) via receptor-mediated signaling $(44,45)$. Furthermore, previous studies have demonstrated that elevated TIMP-1 expression in serum or tissue is associated with poorer outcomes in patients with various types of cancer, including lung cancer (46-50). However, the mechanistic basis for the MMP-independent activity of TIMP1 has yet to be elucidated.

The results of the present study implicated endothelial PECAM-1 in the release of TIMP-1 from the endothelium into the TME, thus resulting in tumor cell proliferation. This effect appeared to involve processes that are dependent on
PECAM-1 homophilic interactions, but are independent of PECAM-1-mediated intracellular signaling.

\section{Materials and methods}

Antibodies. The following antibodies were used in the present study: Anti-mouse TIMP-1 (cat. no. AF980) and anti-human TIMP-1 (cat. no. AF970) (both from R\&D Systems, Inc., Minneapolis, MN, USA); anti-GAPDH (cat. no. sc-25778; Santa Cruz Biotechnology,Inc., Dallas, TX, USA); anti-PECAM-1 antibodies: 390, isolated from hybridoma (32) and Mec 13.3 (cat. no. NB600-1475; Novus Biologicals, LLC, Littleton, CO, USA); anti-mouse cluster of differentiation (CD)16/32 (cat. no. 101319) and rat $\operatorname{IgG} 2 \mathrm{a}, \kappa$ isotype control (cat. no. 400511) (both from BioLegend, Inc., San Diego, CA, USA); rabbit polyclonal anti-proliferating cell nuclear antigen (PCNA) (cat. no. ab18197; Abcam, Cambridge, MA, USA); and biotinylated donkey anti-goat antibody (cat. no. 705-065-147) and biotinylated goat anti-rabbit antibody (cat. no. 111-065-144) (from Jackson ImmunoResearch Laboratories, Inc., West Grove, PA, USA).

Cell lines. Murine EC (MEC) lines, H5V (32), provided by Dr Cecilia Garlanda (Humanitas University, Rozzano, Milan, Italy) through Dr Steven Albelda (University of Pennsylvania, Philadelphia, PA, USA) and CD3 (38), provided by Dr Clement Diglio, (Wayne State University, Detroit, MI, USA), as well as the B16-F10 murine melanoma [CRL-6475, American Type Culture Collection (ATCC), Manassas, VA, USA] and 4T1 murine breast cancer (CRL-2539, ATCC) cell lines were maintained at $37^{\circ} \mathrm{C}$ in an atmosphere containing $5 \% \mathrm{CO}_{2}$. Cells were grown in Dulbecco's modified Eagle's medium (DMEM; Gibco; Thermo Fisher Scientific, Inc., Waltham, MA, USA) containing $1.0 \mathrm{~g} / 1$ glucose, $2 \mathrm{mM}$ L-glutamine, $100 \mathrm{U} / \mathrm{ml}$ penicillin, $0.1 \mu \mathrm{g} / \mathrm{ml}$ streptomycin and $10 \%$ fetal bovine serum (FBS; Sigma-Aldrich; Merck KGaA, Darmstadt, Germany). REN cells (51), a human mesothelioma cell line that has been used as a surrogate for studying ECs $(14,34,52,53)$ were provided by Dr Steven Albelda (University of Pennsylvania), and were grown in RPMI-1640, (Gibco; Thermo Fisher Scientific, Inc.) supplemented with $2 \mathrm{mM}$ L-glutamine, $100 \mathrm{U} / \mathrm{ml}$ penicillin, $0.1 \mu \mathrm{g} / \mathrm{ml}$ streptomycin and 10\% FBS. Previously generated stably transduced REN cell lines expressing wild-type and mutant mouse PECAM-1 were employed (53) and were cultured in RPMI-1640 complete media containing $1 \mu \mathrm{g} / \mathrm{ml}$ puromycin. Primary MECs were isolated from C57BL/6 mouse lungs using fluorescent-activated cell sorting (FACS) as previously described (54) and were cultured in M199 medium (Gibco; Thermo Fisher Scientific, Inc.) containing 15\% FBS, $50 \mu \mathrm{g} / \mathrm{ml}$ endothelial growth factor (BD Biosciences, Franklin Lakes, NJ, USA), $100 \mu \mathrm{g} / \mathrm{ml}$ heparin and $1 \mathrm{mM}$ glutamine. Cells were regularly passaged two times per week in order to maintain them under exponential growth conditions, and cells at passages 2-5 were used for subsequent experiments.

Animals. The present study was approved by the Institutional Animal Care and Utilization Committee at the University of Pennsylvania School of Medicine (Philadelphia, PA, USA). PECAM-1-null mice that had been backcrossed for $>10$ generations onto a C57BL/6 background (55) were provided by Dr Joseph Madri (Yale University, New Haven, CT, USA) 
through Dr Steven Albelda (University of Pennsylvania, Philadelphia, PA, USA). Wild-type mice, also on a C57BL/6 background, were obtained from Taconic Biosciences (Germantown, NY, USA). A total of 12 mice (three male and three female C57BL/6 mice, and three male and three female PECAM-1-null mice; age, 8-10 weeks; weight, 20-30 g) were used in the present study. All mice were maintained under animal protocols approved by the Institutional Animal Care and Use Committee of the University of Pennsylvania (Philadelphia, PA, USA). Animals were housed under standardized conditions with controlled temperature $\left(23^{\circ} \mathrm{C}\right)$ and humidity, under a 12-h light/dark cycle. Animals had free access to water and laboratory diet 5010 .

In vivo model of lung metastasis. An in vivo model of lung metastasis was employed as previously described (38). Briefly, 100,000 B16-F10 melanoma cells in $200 \mu \mathrm{l}$ DMEM were injected into the tail vein of 8-10 week old, male or female, wild-type or PECAM-null mice ( $\mathrm{n}=6 \mathrm{mice} / \mathrm{strain})$. After 21 days, mice were euthanized by $\mathrm{CO}_{2}$ inhalation and the lungs were harvested. The left lung was fixed in $10 \%$ formalin solution for $24 \mathrm{~h}$ at room temperature for histological analysis, whereas the right lung was frozen immediately for protein extraction.

Tumor co-culture assay. For these experiments, 12-well Transwell $0.4 \mu \mathrm{m}$ pore polyester membrane inserts were coated with $125 \mu \mathrm{l}$ Matrigel (both from Corning Incorporated, Corning, NY, USA). After $1 \mathrm{~h}, 1 \times 10^{5}$ cells (primary MECs or a REN cell line) in a total volume of $400 \mu \mathrm{l}$ were seeded on the Transwell inserts with the appropriate media. After $12 \mathrm{~h}$ growth at $37^{\circ} \mathrm{C}$ in an atmosphere containing $5 \% \mathrm{CO}_{2}$, and once capillary-like structures had formed, the tumor cells were labeled with CellTrace ${ }^{\mathrm{TM}}$ Violet Proliferation dye (Thermo Fisher Scientific, Inc.), according to the manufacturer's protocol. The medium in the Transwell inserts was then replaced with $2 \%$ serum-containing DMEM with $50 \mu \mathrm{g} / \mathrm{ml}$ anti-PECAM-1 antibody or IgG, and $1 \times 10^{5}$ labeled tumor cells in $1 \mathrm{ml} 2 \%$ serum-containing DMEM were added to the wells of the 12-well plates containing Transwell inserts. The tumor cells and the cells in the inserts were then cultured together for $48 \mathrm{~h}$, after which the proliferative capacity of the tumor cells was assessed by flow cytometry and the co-culture conditioned media (CM) collected. For the antibody array studies, 6-well polystyrene plates (Corning Incorporated) were coated with $300 \mu 1$ Matrigel (BD Biosciences). After $1 \mathrm{~h}$, $2 \times 10^{5} \mathrm{CD} 3$ MECs were plated, and after $8 \mathrm{~h}, 2 \times 10^{5} \mathrm{~B} 16-\mathrm{F} 10$ cells together with either $200 \mu \mathrm{g} / \mathrm{ml}$ anti-PECAM-1 390 antibody or rat IgG2a, $\kappa$ isotype control were added and co-cultured at $37^{\circ} \mathrm{C}$; co-culture $\mathrm{CM}$ were collected at $72 \mathrm{~h} . \mathrm{CM}$ from the co-cultures were then centrifuged at $12,000 \mathrm{x} \mathrm{g}$ for $10 \mathrm{~min}$ at $4^{\circ} \mathrm{C}$ to remove cell debris. The $\mathrm{CM}$ were stored at $-80^{\circ} \mathrm{C}$ for further study. To analyze the effects of the anti-TIMP-1 antibody on the proliferation of co-culture tumor cells, the cells were incubated with anti-TIMP-1 $(5 \mu \mathrm{g} / \mathrm{ml})$ antibody for $48 \mathrm{~h}$ at $37^{\circ} \mathrm{C}$. This antibody concentration was used based on dose response studies and published literature (56).

FACS analysis. B16-F10 or 4T1 cells (labeled with CellTrace $^{\mathrm{TM}}$ Violet proliferation dye) were detached from tissue culture plates using enzyme-free cell dissociation buffer (Thermo Fisher Scientific, Inc.), washed with PBS and resupended in PBS containing $2 \%$ bovine serum albumin (BSA; Sigma-Aldrich; Merck KGaA). Sytox AADvanced Dead Cell dye (Thermo Fisher Scientific, Inc.) was used to exclude non-viable cells. FACS was performed using the LSR 11 Flow Cytometer (BD Biosciences), with data analysis performed using FlowJo software (version 7.6.5; FlowJo, LLC, Ashland, OR, USA). Cell proliferation was determined by the extent of CellTrace $^{\mathrm{TM}}$ Violet proliferation dye dilution, as determined by FACS analysis. The use of FACS enabled a reliable and efficient, high-throughput analysis of tumor cell proliferation in the tumor co-culture assays, To assess the expression of PECAM-1 on B16-F10 cells and MECs, cells were initially incubated with $1 \mu \mathrm{g} / 10^{6}$ cells anti-mouse CD16/32 for $10 \mathrm{~min}$ at $4^{\circ} \mathrm{C}$ to block non-specific binding to Fc receptors, and were then stained with $10 \mu \mathrm{g} / \mathrm{ml} 390$ or Mec 13.3 antibodies for $30 \mathrm{~min}$ at $4^{\circ} \mathrm{C}$ and subjected to FACS analysis.

CM proliferation assay. To assess the effects of co-culture $\mathrm{CM}$ on tumor cell proliferation, tumor cells were seeded at 7,500 cells/ well (96-well plate) in $50 \mu \mathrm{l} 2 \%$ FBS-containing RPMI media, after which $50 \mu \mathrm{l} \mathrm{CM}$ was added, and cells were cultured for $48 \mathrm{~h}$, at which time the number of viable cells was determined by trypan blue exclusion (57). This method was adopted because $\mathrm{CM}$, depleted of serum-derived factors, evoked a weaker proliferative response compared with fresh media. Therefore, FACS was found to be a less sensitive/reliable method for assessing the proliferative effects of $\mathrm{CM}$ on tumor cells. To determine the effects of an anti-TIMP-1 antibody on the proliferation of tumor cells cultured in the presence of $\mathrm{CM}$, cells were incubated with $2 \mu \mathrm{g} / \mathrm{ml}$ anti-TIMP-1 (58) for $48 \mathrm{~h}$ at $37^{\circ} \mathrm{C}$.

Antibody array. Levels of 308 mouse secreted proteins (MouseL308 Array; cat. no. AAM-BLM-1A-2; RayBiotech, Inc., Norcross, GA, USA,) were measured in triplicate in CM harvested from co-cultures of B16-F10 and CD3 MECs on Matrigel exposed to control IgG or anti-PECAM-1 antibody as aforementioned, according to the manufacturer's protocol. Microsoft Excel (version 14.0; Microsoft Corporation, Redmond, WA, USA) was used for calculation of means and for statistical comparisons, with two-sided Student's t-tests used for group comparisons. Factors whose concentrations were increased $>1.5$-fold or were decreased $<0.65$-fold compared with the control IgG values, in the presence of anti-PECAM-1 antibody, were deemed significantly different from the control, according to the manufacturer's specifications.

Measurement of soluble factors in the co-culture CM. The levels of mouse TIMP-1 (cat. no. DY980), human TIMP-1 (cat. no. DY970), mouse TIMP-2 (cat. no. DY6304), human TIMP-2 (cat. no. DY971), mouse interleukin (IL)-11 (cat. no. DY418), human IL-11 (cat. no. DY218), mouse soluble CD40 (sCD40) (cat no. MCCD40), human sCD40 (cat. no. DY632), mouse Sonic hedgehog (Shh) (cat. no. MSHH00), human Shh (cat. no. DSHH00), mouse chemokine (C-C motif) ligand 4 (CCL4) (cat. no. MMB00) and human CCL4 (cat. no. DY271) in the $\mathrm{CM}$ from tumor cell co-cultures with primary MECs or REN cell lines were determined by ELISA (all from R\&D Systems, Inc.), according to the manufacturer's protocols. 
Western blotting. Frozen lung tissues from each animal were homogenized in radioimmunoprecipitation assay lysis buffer (cat. no. 9806S; Cell Signaling Technology, Inc., Danvers, MA, UA) containing protease inhibitor cocktail, and protein concentration was determined by bicinchoninic acid protein assay (Thermo Fisher Scientific, Inc.). Proteins (50 $\mu \mathrm{g} /$ lane) were then separated by $10 \%$ SDS-PAGE and transferred to nitrocellulose membranes (EMD Millipore, Billerica, MA, USA), which were blocked for $1 \mathrm{~h}$ at room temperature in 5\% non-fat dry milk in TBST buffer (137 mM sodium chloride, $20 \mathrm{mM}$ Tris, $0.1 \%$ Tween-20). Membranes were incubated overnight at $4^{\circ} \mathrm{C}$ with $0.1 \mu \mathrm{g} / \mathrm{ml}$ goat anti-mouse TIMP-1 antibody (cat. no. AF980; R\&D Systems, Inc.), washed for $20 \mathrm{~min}$ and then incubated in horseradish peroxidase (HRP)-conjugated donkey anti-goat secondary antibody (1:10,000; cat. no. sc-2020; Santa Cruz Biotechnology, Inc.). Rabbit anti-GAPDH antibody (1:200; cat. no. sc-25778; Santa Cruz Biotechnology, Inc.), followed by HRP-conjugated goat anti-rabbit secondary antibody (1:10,000; cat. no. HAF008; R\&D Systems, Inc.), was used as a loading control. After washing, the blots were then developed with enhanced chemiluminescence (Amersham: GE Healthcare, Chicago, IL, USA), according to the manufacturer's protocol. Protein expression was normalized to GAPDH. Protein bands were semi-quantified using ImageJ (1.51S) analysis tool (National Institutes of Health, Bethesda, MD, USA).

Immunohistochemical staining and analysis. Mouse lung tissues were fixed in $10 \%$ formalin for $24 \mathrm{~h}$ at room temperature, embedded in paraffin and were cut into $6-\mu \mathrm{m}$ sections for staining. Immunohistochemistry was performed using the ABC Vectastain kit (Vector Laboratories, Inc., Burlingame, CA, USA). Briefly, tissue sections were deparaffinized with xylene and a graded series of ethanol. Antigen retrieval was performed in $10 \mathrm{mM}$ citrate buffer ( $\mathrm{pH} \mathrm{6.0)}$ ) for $20 \mathrm{~min}$ at 90-94 ${ }^{\circ} \mathrm{C}$ (Dako; Agilent Technologies, Inc., Santa Clara, CA, USA). Endogenous peroxidase activity was blocked in tissue sections with endogenous avidin biotin. Dako wash buffer (Dako; Agilent Technologies, Inc.) was used for all washing steps. To detect mouse TIMP-1, sections were blocked with 5\% donkey serum (cat. no. 0030-01; Southern Biotech, Birmingham, AL, USA) for $1 \mathrm{~h}$ at room temperature, in order to block non-specific protein binding, and were immunolabeled overnight at $4^{\circ} \mathrm{C}$ with goat anti-mouse TIMP-1 antibody (1:50 dilution), followed by $1 \mathrm{~h}$ incubation at room temperature with a 1:250 dilution of biotinylated donkey anti-goat antibody, which was visualized using the Vectastain ABC reagent (30 min at room temperature; reagent was diluted by mixing $100 \mu \mathrm{l}$ of each reagent $\mathrm{A}$ and $\mathrm{B}$ in $5 \mathrm{ml}$ PBS) and VIP peroxidase substrate kit (Vector Laboratories, Inc.). For detection of PCNA, sections were immunolabeled overnight at $4^{\circ} \mathrm{C}$ with PCNA antibody (1:200) in 2\% BSA-PBS, followed by biotinylated goat anti rabbit antibody (1:500) for $1 \mathrm{~h}$ at room temperature and $\mathrm{ABC}$ reagent for $30 \mathrm{~min}$ at room temperature. Following detection with Vectastain Elite ABC kit and DAB HRP substrates (Vector Laboratories, Inc.), the sections were counterstained with methyl green. The slides were then mounted with Vectastain permanent mounting media and photomicrographs were captured under a Nikon E600 photomicroscope (Nikon Corporation, Tokyo, Japan) at x20 magnification. For the analysis of PCNA staining, tissue sections from the lungs of five wild-type or PECAM-1-null mice were searched to identify pre-angiogenic tumor nodules of comparable size to control for the effects of tumor size on cell proliferation and the anti-angiogenic effects of the loss of PECAM-1. To determine the intensity of staining, procedures were followed as previously described (59). Briefly, the ImageJ (1.51S) analysis tool (National Institutes of Health) was used, which allows the user to set the threshold for color saturation, as well as the upper and lower limits for the intensities of weak- and strong-positive pixels. These thresholds were set using positive and negative control tissues. Raw data were obtained in terms of the number of positive pixels and intensity of positive pixels, which were normalized to the number of total pixels counted. Hematoxylin and eosin staining was performed on paraffin-embedded tissue sections at the Pathology Core Lab, Children's Hospital of Philadelphia (Philadelphia, PA, USA).

Statistical analysis. Statistical analyses were conducted using GraphPad Prism 5 software (version 5.01; GraphPad Software, Inc., CA, USA). The differences between two groups were analyzed using two-tailed Student's t-test, and differences between more than two groups were analyzed using one-way analysis of variance with Tukey's post hoc test. $\mathrm{P}<0.05$ was considered to indicate a statistically significant difference.

\section{Results}

Reduced tumor cell proliferation in non-vascularized, pre-angiogenic lesions in PECAM-1-null mice. Since anti-PECAM-1 antibody inhibits in vivo tumor cell proliferation(38),PCNA staining was performed on the lungs of wild-type and PECAM-1-null mice bearing B16-F10 tumors, in order to assess tumor cell proliferation (Fig. 1). For this analysis, small, non-vascularized, pre-angiogenic nodules of comparable size were selected from the wild-type and PECAM-1-null mice, in order to control for the effects of tumor size on cell proliferation, as well as to assess the effects of the loss of PECAM-1 on tumor cell proliferation, independent of effects on the tumor resulting from the suppression of PECAM-1-dependent angiogenesis. In nodules of comparable size, it was revealed that the nuclei of the tumor cells in the wild-type animals were stained more frequently for PCNA compared with the tumor cells in the PECAM-1-null mice (Fig. 1). These findings indicated that loss of PECAM-1 may be associated with inhibition of tumor cell proliferation. Additionally, although identically cultured and prepared B16-F10 cells were injected, differences were noted in tumor cell histology in the wild-type and PECAM-1-null mice (Fig. 2). Specifically, it was consistently observed that the B16-F10 cells in the wild-type animals were larger, possessing larger nuclei, with a vacuolated, irregular, chromatin pattern and prominent eosinophilic nucleoli. Conversely, the tumor cells in the PECAM-1-null mice were more compact, with smaller nuclei that demonstrated a more dispersed, evenly-stained chromatin pattern (Fig. 2). These differences between the wild-type and PECAM-1-null mice were detected in small non-vascularized lesions, as well as in larger vascularized tumor nodules of comparable sizes from the two strains. Together with our previous study (38), these data provide further evidence to suggest that endothelial 
A

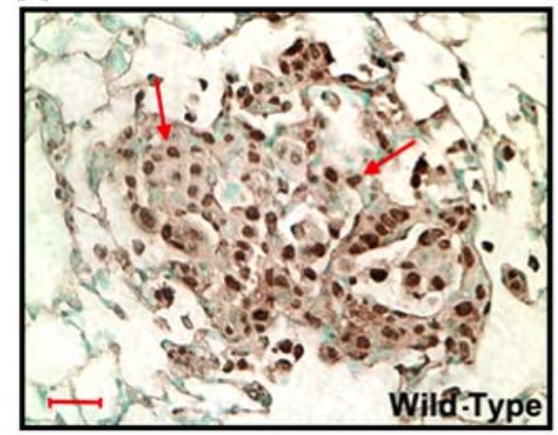

B

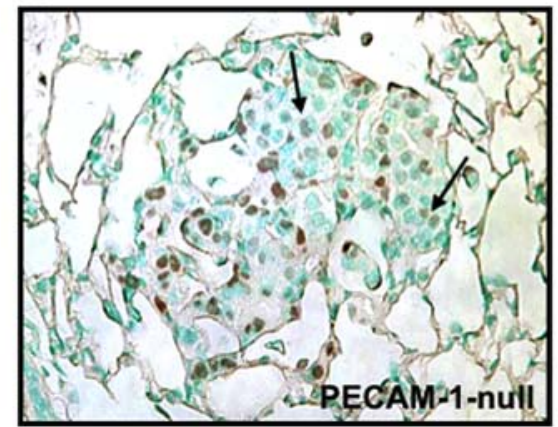

C

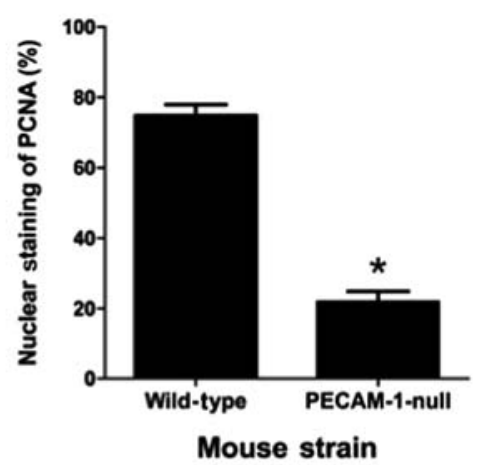

Figure 1. B16-F10 melanoma cell proliferation in wild-type and PECAM-1-null mice. Small, pre-angiogenic, sub-clinical, metastatic B16-F10 tumor nodules in the lungs of (A) wild-type and (B) PECAM-1-null mice were stained for PCNA, as a marker of cell proliferation. Scale bar, $20 \mu \mathrm{m}$. Tissue sections from the lungs of five wild-type or PECAM-1-null mice were searched to identify pre-angiogenic tumor nodules of comparable size, in order to control for the effects of tumor size on cell proliferation and the anti-angiogenic effects of PECAM-1 loss. The nuclei of tumor cells in the wild-type mice were more frequently and intensely stained for PCNA (brown staining, red arrows) compared with in the nuclei of tumor cells in the PECAM-1-null mice (black arrows); (C) 75\% of the wild-type tumor nuclei vs. $\sim 22 \%$ of the PECAM-1-null tumor nuclei were positive for PCNA. Data are presented as the means \pm standard error, $\mathrm{n}=3$. ${ }^{*} \mathrm{P}<0.0001$ compared with the wild-type mice. PCNA, proliferating cell nuclear antigen; PECAM-1, platelet endothelial cell adhesion molecule-1.
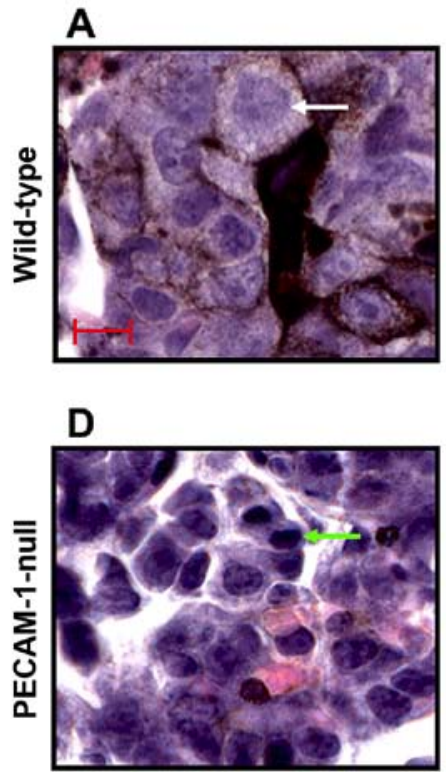

\section{B}

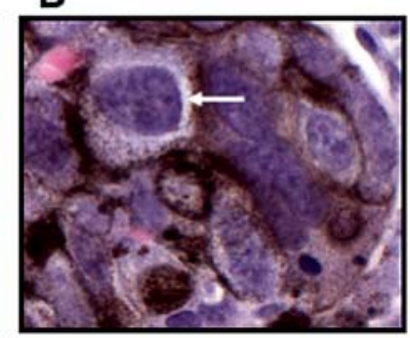

E

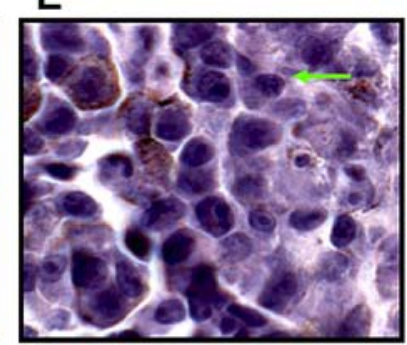

C

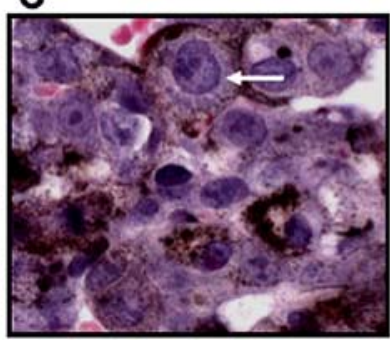

$\mathbf{F}$

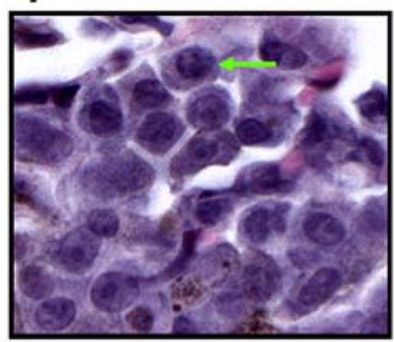

Figure 2. Histological analysis of B16-F10 melanoma cells in the wild-type and PECAM-1-null mice. Hematoxylin and eosin staining of metastatic B16-F10 melanoma tumor nodules in (A-C) wild-type and (D-F) PECAM-1-null mice. B16-F10 tumor cells in the wild-type mice were larger and possessed larger nuclei, with a vacuolated, irregular, chromatin pattern and prominent eosinophilic nucleoli (white arrows). Tumor cells in the PECAM-1-null mice, were more compact, with smaller nuclei that demonstrated a more dispersed, evenly-stained chromatin pattern (green arrows). Melanin pigmentation is present in panels A-C. Magnification, x40; scale bar, $5 \mu \mathrm{m}$. PECAM-1, platelet endothelial cell adhesion molecule-1.

PECAM-1 modulates the TME to promote a proliferative phenotype for metastatic tumor cells.
PECAM-1 mediates the release of soluble mediators that stimulate in vitro tumor cell proliferation. To understand the 
A

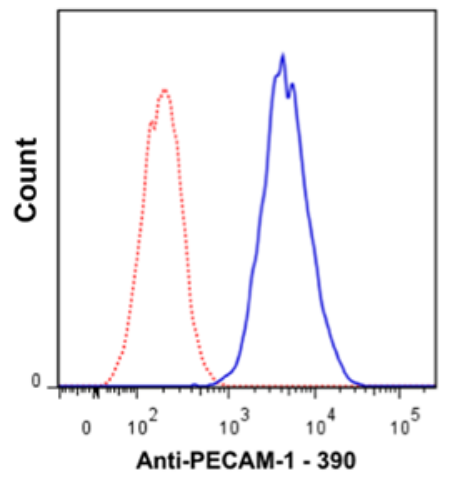

MEC

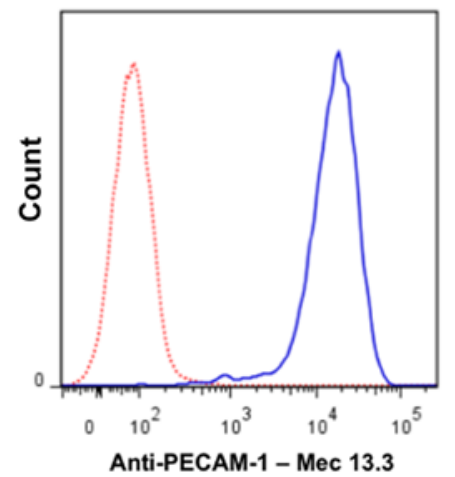

B

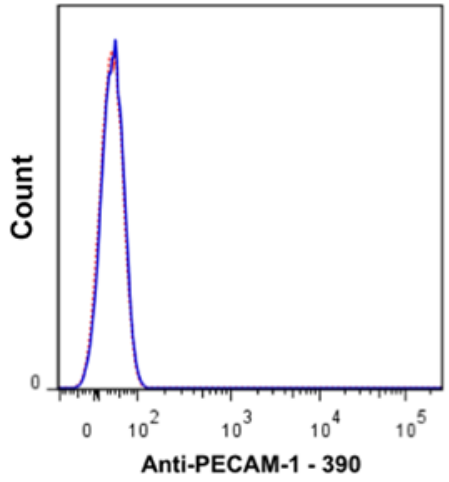

B16-F10

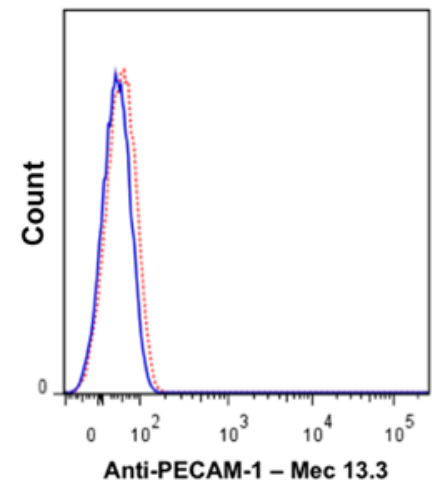

Figure 3. FACS analysis of MECs and B16-F10 melanoma cells stained with anti-PECAM-1 antibodies. Tracings for the FACS analyses of (A) the MEC line, H5V and (B) B16-F10 melanoma cells stained with 390 and Mec 13.3 anti-PECAM-1 antibodies. Antibody tracings are in blue, whereas the dotted red tracing represents isotype IgG control. Although both antibodies bound to the MECs, there was no detectable binding to the B16-F10 cells compared with the IgG control. FACS, fluorescence-activated cell sorting; IgG, immunoglobulin G; MECs, murine endothelial cells; PECAM-1, platelet endothelial cell adhesion molecule-1.

mechanisms by which PECAM-1 might modify the TME to promote tumor cell proliferation, an in vitro co-culture assay was initially developed in which tumor cells and transformed MECs were cultured together on Matrigel (38). In this initial study (38), the 390 anti-PECAM-1 antibody inhibited B16-F10 melanoma cell proliferation in the co-cultures, and the proliferation of B16-F10 melanoma cells cultured in CM from antibody treated co-cultures was reduced. It has previously been reported that antibody 390 does not bind to tumor cells and/or inhibit tumor cell proliferation in the absence of a co-culture system (38). Since the publication of this previous paper, there have been reports that a small subpopulation $(\sim 0.2 \%)$ of B16-F10 melanoma cells express PECAM-1 (60). However, the present study did not detect PECAM-1 expression on the B16-F10 cells (Fig. 3), as assessed by FACS analysis using the anti-PECAM-1 antibodies, 390 and Mec 13.3, which map to different epitopes (61).

To confirm these findings with primary MECs, and to determine the role of direct tumor cell/EC contact compared with tumor cell/EC crosstalk mediated by soluble mediators, the assay was adapted to one in which Transwell inserts with primary MECs plated on Matrigel were placed in the wells of 12-well plates containing tumor cells (Fig. 4). The presence of primary MECs in the co-culture system resulted in a 2-3-fold increase in B16-F10 tumor cell proliferation, as determined by FACS analysis, an effect that was significantly inhibited by anti-PECAM-1 antibody (50 $\mu \mathrm{g} / \mathrm{ml})$ (Fig. 4A), which did not affect the viability of ECs (data not shown). To confirm the involvement of soluble factors, B16-F10 cells were grown in CM from either control IgG or anti-PECAM-1 antibody-treated co-cultures. For B16-F10 cells cultured in CM from anti-PECAM-1 antibody-treated co-cultures, cell proliferation was reduced by $30 \%$ compared with control CM (Fig. 4C). Similar results were observed with primary MECs co-cultured with 4T1 breast cancer cells (Fig. 4B and D).

PECAM-1, through homophilic ligand interactions, induces the release of soluble mediators that stimulate in vitro tumor cell proliferation. The present study next aimed to confirm the co-culture findings obtained with primary MECs, and to determine the molecular basis of PECAM-1 activity in promoting tumor cell proliferation. Specifically, tumor co-culture studies were performed with REN cells, a non-PECAM-1 expressing human mesothelioma cell line, which has been used as an endothelial surrogate for studying the function of PECAM-1 $(14,34,52,53)$. REN cells were transduced to express wild-type mouse PECAM-1 (REN-MP), or mouse PECAM-1 in which homophilic binding ( $\left.\mathrm{REN}-\mathrm{MP}_{\triangle \mathrm{Hom}}\right)$, $\mathrm{GAG} /$ heterophilic binding $\left(\mathrm{REN}-\mathrm{MP}_{\mathrm{AHet}}\right)$ or intracellular signaling (REN-MPY $\rightarrow$ F) had been disabled (53) (Fig. 5). An advantage of this system is that the REN cells are of human origin, whereas the tumor cells are murine. This therefore allows for targeting of the 'vascular' (REN cells) or tumor components of the system with human versus murine specific reagents, and can be used to determine the cellular source of soluble factors. In co-culture studies (Fig. 5A), it was 

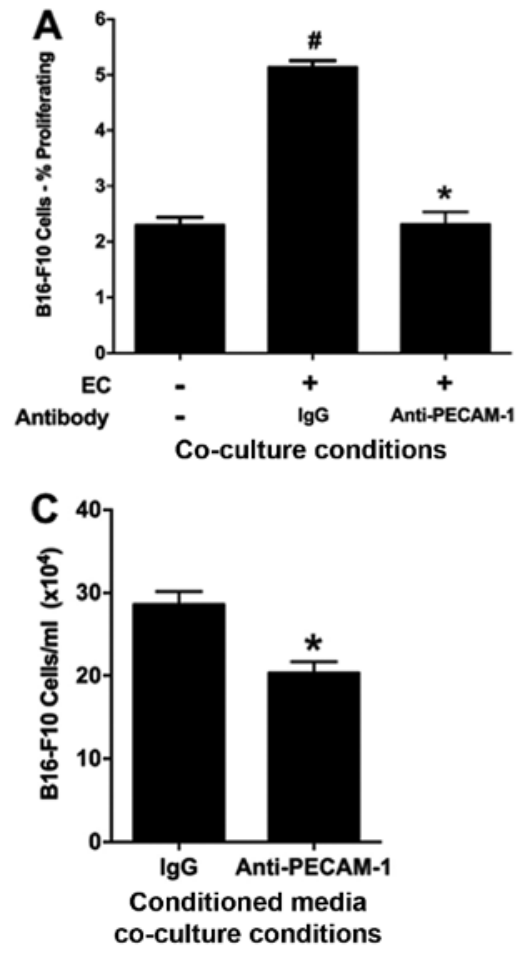
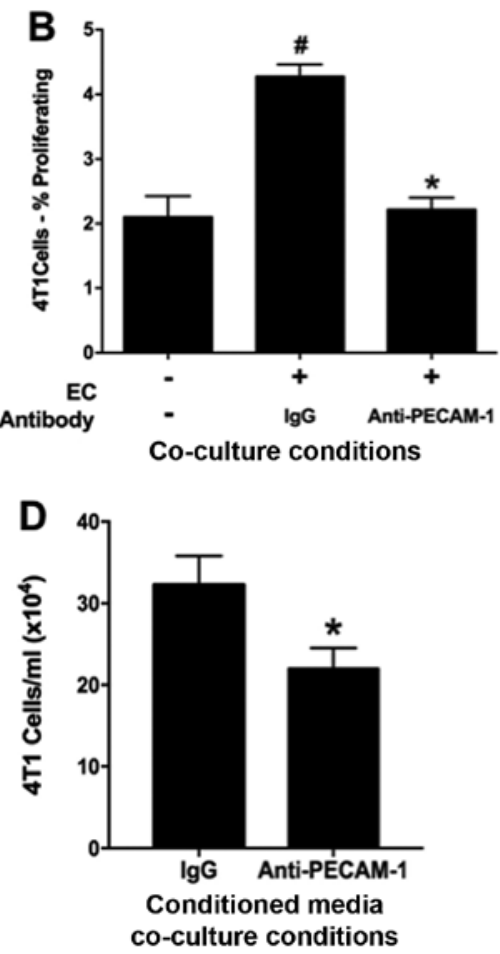

Figure 4. Tumor cell proliferation in co-culture with MECs. The proliferation of (A) B16-F10 melanoma cells and (B) 4T1 breast cancer cells co-cultured with MECs was increased, indicating that the presence of MECs stimulates tumor cell proliferation. Proliferation was inhibited by anti-PECAM-1 antibody $(50 \mu \mathrm{g} / \mathrm{ml})$. Data are presented as the means \pm standard error; $\mathrm{n}=3-6$. ${ }^{~} \mathrm{P}<0.0001$ compared with the no MEC/no antibody condition; ${ }^{*} \mathrm{P}<0.0001 \mathrm{compared}$ with the MEC/IgG condition. (C) B16-F10 melanoma cells and (D) 4T1 breast cancer cells were cultured in CM from tumor/MEC co-cultures that had been treated with IgG or anti-PECAM-1, after which proliferation was detected. B16-F10 and 4T1 tumor cell proliferation was reduced when cultured in CM derived from anti-PECAM-1-treated co-cultures compared with the $\mathrm{IgG}$ controls. Data are presented as the means \pm standard error; $\mathrm{n}=3$ or 4 . * $\mathrm{P}<0.0005$ compared with the IgG condition. CM, conditioned media; IgG, immunoglobulin G; MECs, murine endothelial cells; PECAM-1, platelet endothelial cell adhesion molecule-1.
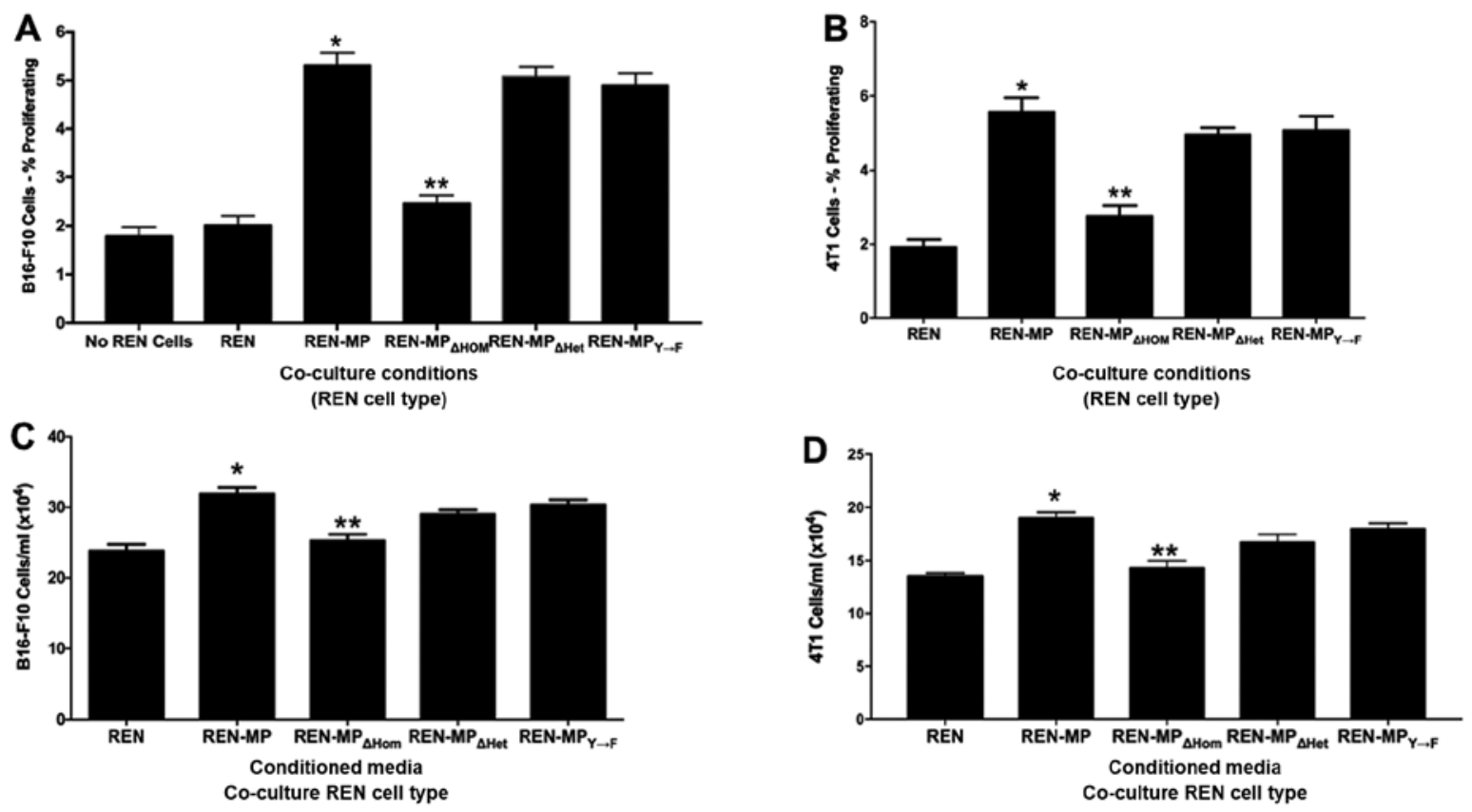

Figure 5. B16-F10 melanoma cell proliferation in co-culture with REN cells expressing wild-type or mutant PECAM-1. The proliferation of (A) B16-F10 melanoma cells and (B) 4T1 breast cancer cells co-cultured with control REN cells or REN cells expressing wild-type or mutant PECAM-1. Tumor cell proliferation was stimulated by REN-MP cell; conversely, proliferation was reduced in cells co-cultured with REN-MP $\mathrm{AHom}_{\mathrm{H}}$, but not in cells co-cultured with

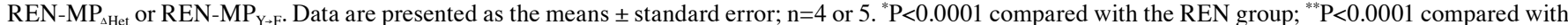
the REN-MP group. (C) B16-F10 melanoma cells and (D) 4T1 breast cancer cells were cultured in CM derived from co-cultures of tumor cells with various REN cell lines. Tumor cell proliferation was increased when cultured in CM derived from REN-MP co-cultures compared with REN co-cultures, an effect that was not seen in $\mathrm{CM}$ obtained from co-cultures with the $\mathrm{REN}-\mathrm{MP}_{\triangle \mathrm{Hom}}$ cell line. Data are presented as the means \pm standard error; $\mathrm{n}=4$. ${ }^{*} \mathrm{P}<0.0001$ compared with the REN group; ${ }^{* *} \mathrm{P}<0.0001$ compared with the REN-MP group. CM, conditioned media; h, human; IgG, immunoglobulin G; PECAM-1, platelet endothelial cell adhesion molecule-1; REN-MP, REN cells expressing PECAM-1; REN-MP ${ }_{\triangle \mathrm{Het}}$, REN cells in which glycosaminoglycan/heterophilic binding was disabled;

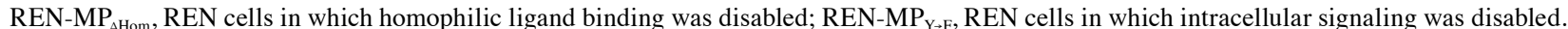



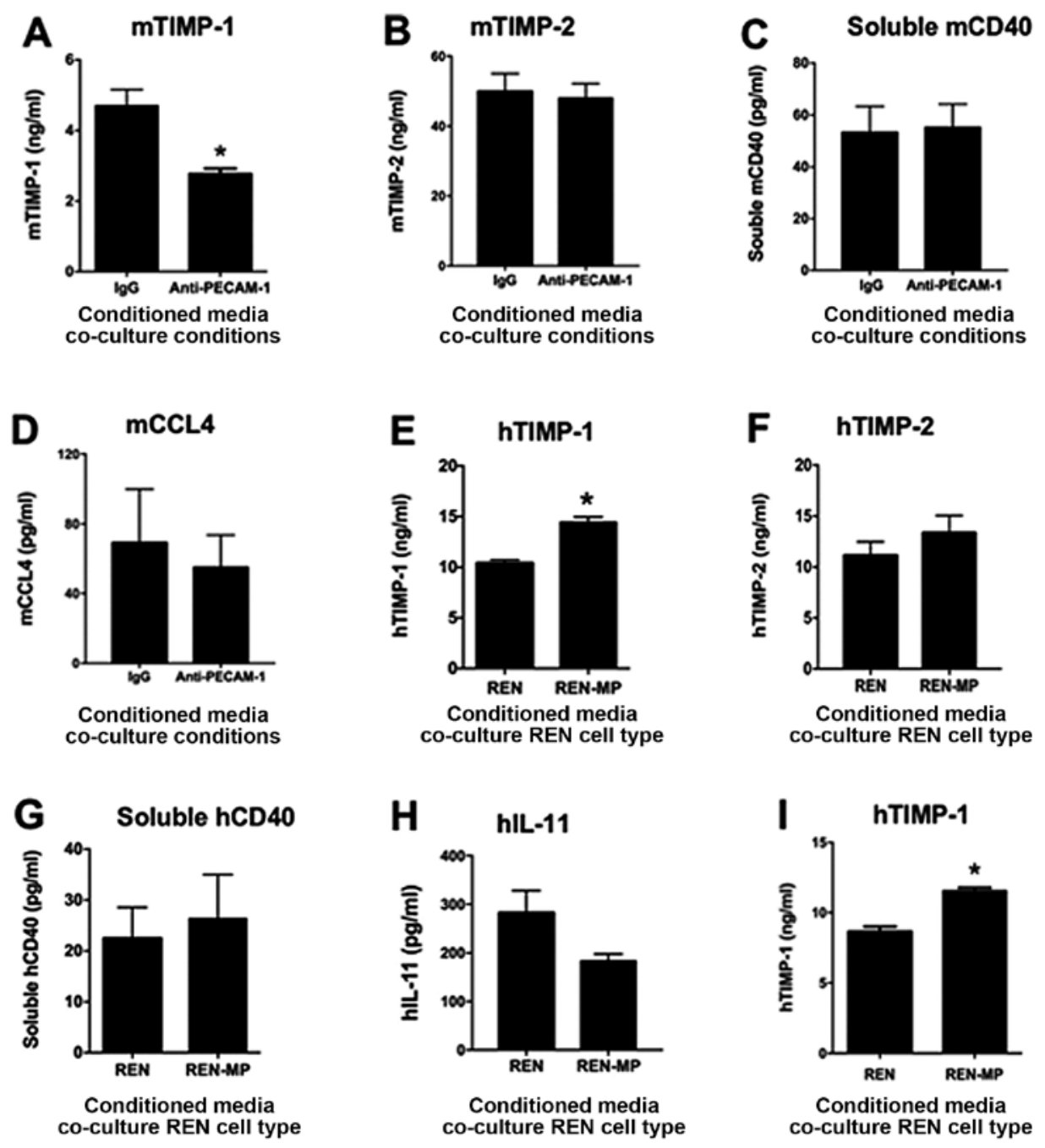

Figure 6. Expression levels of soluble factors in the CM from co-cultures of B16-10 melanoma cells with MEC or REN cell lines. (A-D) From MEC/B16-F10 melanoma co-cultures, the CM concentrations of mTIMP-1, mTIMP-2, soluble mCD40 and mCCL4 were detected. (A) mTIMP-1 levels were decreased in $\mathrm{CM}$ derived from B16-F10/MEC co-cultures treated with anti-PECAM-1 compared with the IgG control; (B) mTIMP-2, (C) soluble mCD40 and (D) mCCL4 levels were not altered. (E-H) From B16-F10/REN or REN-MP co-cultures, the CM concentrations of hTIMP-1, hTIMP-2, soluble hCD40 and hIL-11 were determined. (E) hTIMP-1 levels were increased in CM obtained from B16-F10/REN-MP co-cultures compared with the REN control; levels of (F) hTIMP-2, (G) soluble hCD40 and (H) IL11 in the CM were not significantly altered by the presence of REN-MP in the co-cultures. (I) hTIMP-1 levels were also increased in the CM obtained from co-cultures of 4T1 cells and REN-MP compared with the REN control. Data are presented as the means \pm standard error of the mean; $\mathrm{n}=4$. " $\mathrm{P}<0.0005$ compared with IgG or REN cells. CCL4, chemokine (C-C motif) ligand 4; CD40, cluster of differentiation; CM, conditioned media; IL-11, interleukin-11; m, murine; MECs, murine endothelial cells; PECAM-1, platelet endothelial cell adhesion molecule-1; REN-MP, REN cells expressing PECAM-1; TIMP-1, TIMP metallopeptidase inhibitor-1.

demonstrated that REN-MP stimulated the proliferation of B16-F10 melanoma cells by 2-3-fold, with CM from these co-cultures stimulating the proliferation of cultured B16-F10 cells by $\sim 30 \%$ (Fig. 5C). The stimulatory effects of PECAM-1 on tumor cell proliferation were lost if PECAM-1-dependent homophilic binding was disrupted, but remained preserved despite disruption of PECAM-1-dependent GAG/heterophilic ligand binding or intracellular signaling (Fig. 5A). Consistent with this finding, CM derived from the REN-MP ${ }_{\triangle \mathrm{Hom}}$ failed to stimulate B16-F10 proliferation, whereas proliferation was preserved in response to CM from the REN-MP ${ }_{\triangle \mathrm{Het}}$ and REN-MPY $\rightarrow$ F co-cultures (Fig. 5C). Furthermore, similar results were observed with the 4T1 murine breast cancer line (Fig. 5B and D). These data suggested that the presence of PECAM-1 promotes tumor cell proliferation by modulating the release of soluble factors through processes that involve PECAM-1-dependent homophilic ligand interactions, but which are independent of signaling mediated by PECAM-1-tyrosine phosphorylation.

Identification of TIMP-1 as a potential mediator of the pro-proliferative effects of PECAM-1. The levels of 308 mouse-secreted proteins were measured in CM harvested from B16-F10 and CD3 MEC co-cultures after exposure to either anti-mouse PECAM-1 or isotype control antibody. Using an antibody affinity array, it was revealed that the concentrations of 21 factors were significantly downregulated by anti-PECAM-1 antibody, compared with the IgG control (Table I). In addition, 24 upregulated factors were identified (data not shown), analyses of which are the focus of separate, ongoing studies. The list of downregulated factors included six potential endothelial-derived factors with reported involvement in cell proliferation and/or tumor metastasis: TIMP-1 (41-43,46-50,62), TIMP-2 (62,63), IL-11 $(64,65)$, 
Table I. Antibody affinity array analysis of conditioned media from B16-F10/murine endothelial cell co-cultures, to identify PECAM-1-regulated soluble factors.

\begin{tabular}{rlcc}
\hline No. & \multicolumn{1}{c}{ Protein } & Fold decrease & P-value \\
\hline 1 & Soluble CD40 & 0.58 & 0.0420 \\
2 & IL-11 & 0.55 & 0.0029 \\
3 & Eotaxin-2 & 0.51 & 0.0493 \\
4 & Cripto & 0.46 & 0.0446 \\
5 & CCR10 & 0.46 & 0.0126 \\
6 & TSLPR & 0.35 & 0.0380 \\
7 & Shh-N & 0.33 & 0.0269 \\
8 & Decorin & 0.32 & 0.0264 \\
9 & VEGFR3 & 0.27 & 0.0347 \\
10 & BAFFR/TNFRSF13C & 0.26 & 0.0279 \\
11 & IL-23 R & 0.21 & 0.0360 \\
12 & Insulin & 0.21 & 0.0027 \\
13 & CD30 L & 0.21 & 0.0286 \\
14 & CCL4/MIP-1 $\beta$ & 0.19 & 0.0476 \\
15 & TIMP-2 & 0.19 & 0.0221 \\
16 & TIMP-1 & 0.18 & 0.0187 \\
17 & TSLP & 0.18 & 0.0333 \\
18 & VEGF-D & 0.15 & 0.0098 \\
19 & TARC & 0.15 & 0.0114 \\
20 & TRANCE/TNFSF11 & 0.07 & 0.0226 \\
21 & PDGFR $\alpha$ & 0.01 & 0.0226 \\
& & & \\
\hline & & &
\end{tabular}

Listed are 21 downregulated factors whose expression levels were $<0.65$-fold decreased in the presence of the anti-PECAM-1 antibody compared with the control values (IgG control). The level of inhibition resulting from the presence of anti-PECAM-1 increases from the top to the bottom of the table. PECAM-1, platelet endothelial cell adhesion molecule 1 .

soluble CD40 (sCD40) $(66,67)$, Shh $(68,69)$ and CCL4 $(70,71)$, whose expression levels were specifically decreased in the presence of anti-PECAM-1, and may therefore be potentially regulated by PECAM-1. Subsequently, the mouse or human concentrations of these six proteins in $\mathrm{CM}$ from antibody-treated tumor/MEC co-cultures or tumor/REN-MP cell co-cultures were determined by ELISA (Fig. 6). It was revealed that levels of mouse (m)TIMP-1, but not those of mTIMP-2, soluble mCD40 or mCCL4, were reduced in the CM from anti-PECAM-1 antibody-treated B16-F10/MEC co-cultures compared with IgG (Fig. 6A-D). mIL-11 and $\mathrm{mShh}$ were not detected in these CM (data not shown). These data were supported by the finding that human (h)TIMP-1 levels were increased in the B16-F10/REN-MP co-cultures compared to the control REN cells (Fig. 6E). In addition, REN-MP cells mediated a significant increase in the release of hTIMP-1 compared to REN cells in co-culture with 4T1 cells (Fig. 6I). Conversely, no statistically significant differences between REN and REN-MP cells were detected with regards to the levels of TIMP-2, soluble CD40 and IL-11 proteins (Figs. 6F-H), and CCL4 and Shh were not detected (data not shown). Taken together, these data indicated that
TIMP-1 may be a soluble mediator of the pro-proliferative effects of endothelial PECAM-1.

Targeting TIMP-1 inhibits PECAM-1-mediated tumor cell proliferation. To directly confirm the involvement of TIMP-1 in mediating the tumor proliferative effects of PECAM-1, B16-F10/REN-MP co-cultures were treated with control IgG or anti-hTIMP-1, in order to specifically target hTIMP-1 expressed by REN cells in the co-culture assay (Fig. 7). The results demonstrated that anti-hTIMP-1 antibody inhibited stimulation of B16-F10 cell proliferation mediated by REN-MP (Fig. 7A). Furthermore, anti-hTIMP-1 antibody, but not $\mathrm{IgG}$, blocked the stimulation of B16-F10 cell proliferation by CM derived from B16-F10/REN-MP co-cultures (Fig. 7C). Comparable inhibitory effects of the anti-hTIMP-1 antibody were detected in 4T1/REN-MP co-cultures (Fig. 7B and D).

Decreased metastatic tumor TIMP-1 expression in PECAM-1-null mice. To explore the potential in vivo significance of the findings of the in vitro experiments, TIMP-1 expression was detected in the lungs of wild-type and PECAM-1-null mice, which were injected via the tail vein with B16-F10 melanoma cells to model lung metastases. Western blot analysis of cell lysates of the right lung demonstrated negligible TIMP-1 protein in the absence of tumors (Fig. 8A). Conversely, TIMP-1 protein expression was markedly increased in the presence of B16-F10 tumors in the lungs; however, TIMP-1 protein expression was significantly decreased in the lungs of tumor-bearing PECAM-1-null mice compared with the wild-type mice (Fig. 8). TIMP-1 expression was further analyzed by immunohistochemical staining (Fig. 9). Outside of tumors, TIMP-1 staining in the lungs was minimal (Figs. 9A and D, arrows). However, tumor foci in the wild-type mice were intensely stained for TIMP-1 (Figs. 9A-C), whereas TIMP-1 staining was significantly reduced in the tumors of PECAM-1-null mice (Figs. 9D-G). Notably, there were no differences in the distribution (peri-arteriolar vs. sub-pleural) of tumors in the lungs. Since immunostaining of cultured B16-F10 demonstrated negligible TIMP-1 expression (data not shown), the TIMP-1 staining of tumor foci may represent TIMP-1 derived from the microenvironment that is peri-cellular, membrane-associated and/or internalized rather than endogenously produced by the tumor. Taken together with the co-culture studies, these data implicated PECAM-1 in the regulation of TIMP-1 in the TME of metastatic tumors.

\section{Discussion}

The vast majority of cases of cancer-associated mortality are caused by the effects of metastatic, rather than local, disease (8); therefore, developing a more complete understanding of the cascade of events involved in tumor metastasis is critical to the development of novel treatments for patients with advanced cancer. One area that remains incompletely understood is the progression of metastatic, sub-clinical, microscopic tumor foci to macroscopic, clinically apparent and debilitating tumors, and the role that the TME has in this process (1-8). There is, however, evidence that PECAM-1 expressed on the vascular endothelium acts as a mediator of the late progression of metastatic tumors (38). Notably, this activity is mediated by 

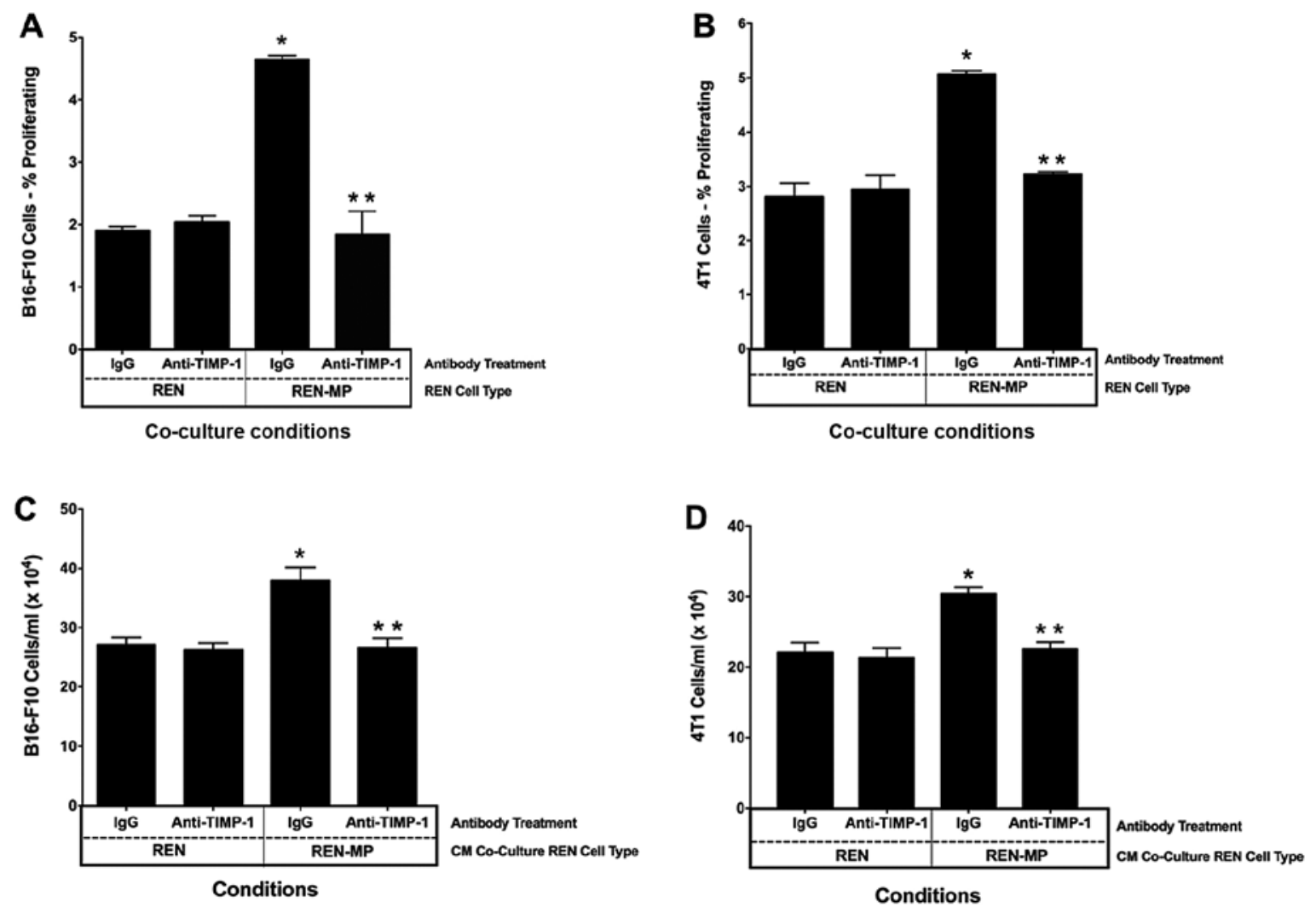

Figure 7. Effects of anti-TIMP-1 on PECAM-1-mediated tumor cell proliferation. In co-cultures of (A) B16-F10 or (B) 4 T1 and REN cell lines, anti-TIMP-1 antibody inhibited stimulation of B16-F10 and $4 \mathrm{~T} 1$ cell proliferation mediated by REN-MP. Data are presented as the means \pm standard error; $\mathrm{n}=3$. " $\mathrm{P}<0.01$ compared with the REN/IgG condition; ${ }^{* *} \mathrm{P}<0.05$ compared with the REN-MP/IgG condition. Anti-TIMP-1 antibody treatment, but not IgG, inhibited the stimulation of (C) B16-F10 and (D) 4T1 cell proliferation by CM derived from B16-F10 or 4T1 and REN-MP co-cultures. Data are presented as the means \pm standard error; $n=4 .{ }^{*} \mathrm{P}<0.0001$ compared with the $\mathrm{REN} / \mathrm{IgG}$ condition; ${ }^{* *} \mathrm{P}<0.0001$ compared with the REN-MP/IgG condition. CM, conditioned media; IgG, immunoglobulin G; PECAM-1, platelet endothelial cell adhesion molecule-1; REN-MP, REN cells expressing PECAM-1; TIMP-1, TIMP metallopeptidase inhibitor-1.

\section{A} TIMP-1
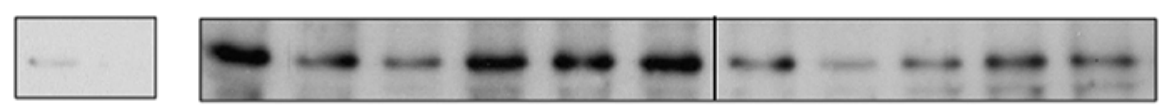

GAPDH
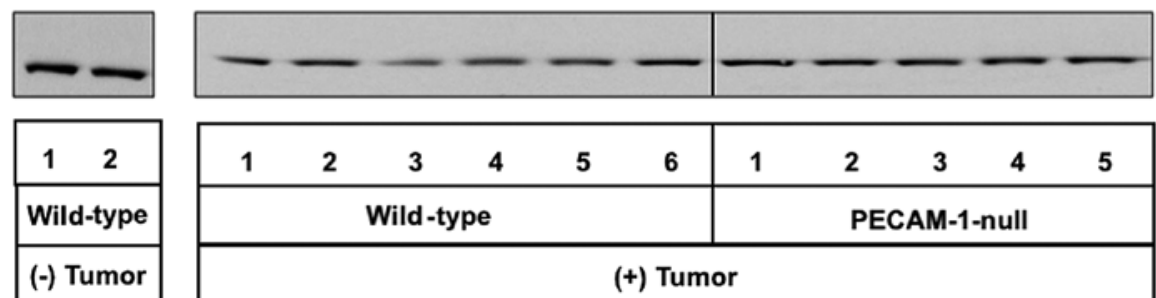

\begin{tabular}{|llllll|lllll|}
\hline 1 & 2 & 3 & 4 & 5 & 6 & 1 & 2 & 3 & 4 & 5 \\
\hline \multicolumn{3}{|c|}{ Wild-type } & & \multicolumn{5}{|c|}{ PECAM-1-null } \\
\hline \multicolumn{1}{|c|}{$(+)$ Tumor } \\
\hline
\end{tabular}

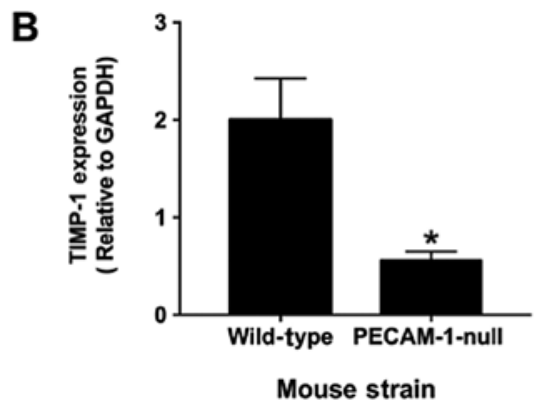

Figure 8. TIMP-1 protein expression in the lungs of mice bearing B16-F10 tumors. (A) Cell lysates from the right lungs of wild-type and PECAM-1-null mice were immunoblotted with anti-mouse TIMP-1 antibody. In the absence of tumor, TIMP-1 expression was negligible but was significantly increased in wild-type animals when B16-F10 tumors are present. (B) Protein expression levels of TIMP-1 were significantly reduced in the PECAM-1-null mice, as confirmed by densitometric analysis; expression levels of TIMP-1 were normalized to GAPDH. Data are presented as the means \pm standard error; $n=5$ or 6 . "P<0.02 compared with the wild-type group. PECAM-1, platelet endothelial cell adhesion molecule-1; TIMP-1, TIMP metallopeptidase inhibitor-1. 
A

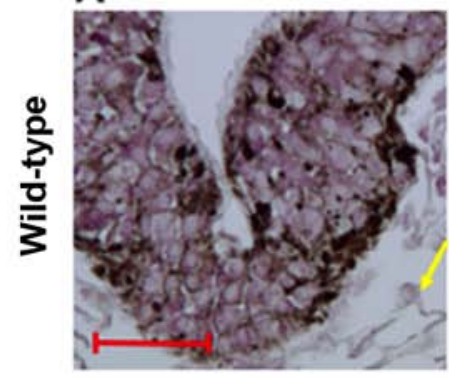

E

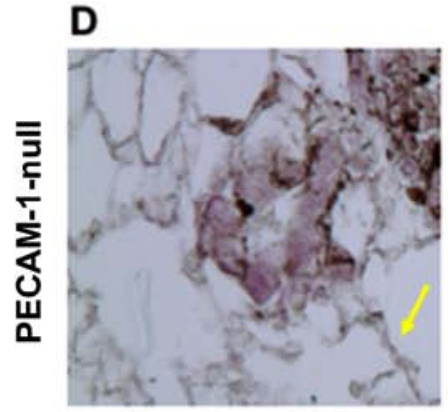

B
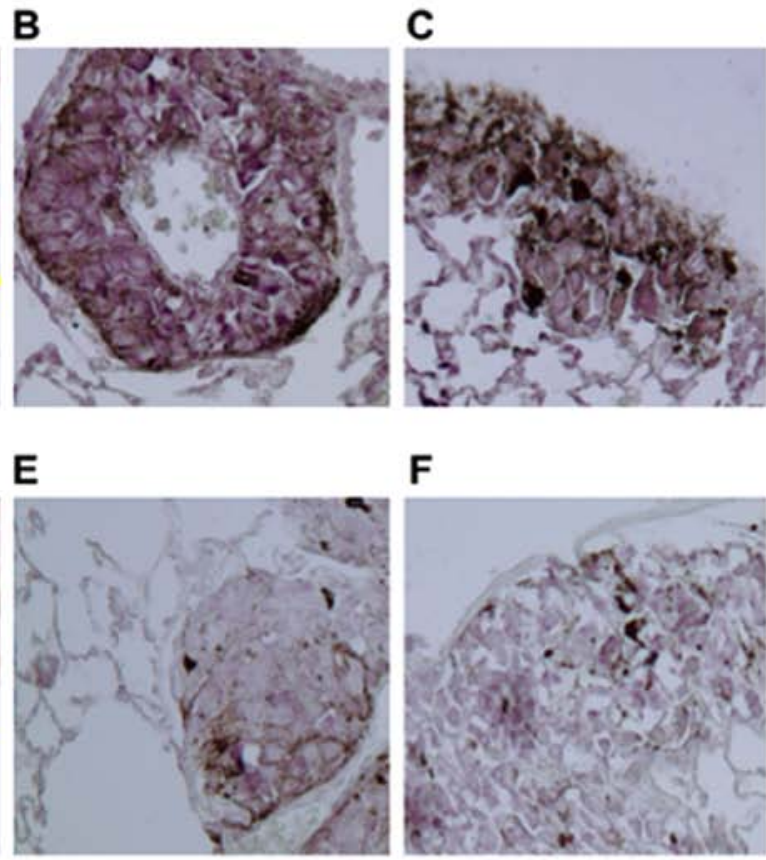

$\mathbf{F}$

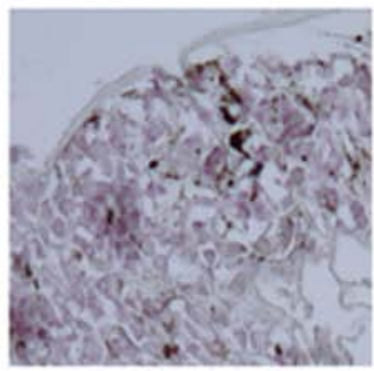

G

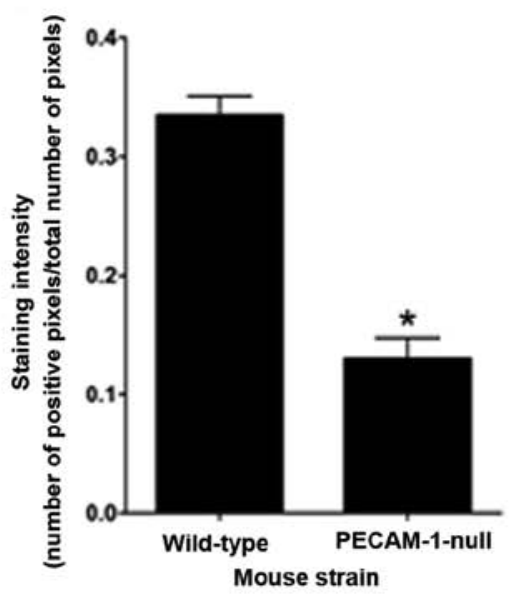

Figure 9. Immunohistochemical staining of TIMP-1 in the lungs of mice bearing B16-F10 tumors. Tumor-bearing lungs of wild-type and PECAM-1-null mice were immunohistochemically stained for murine TIMP-1. (A and D) Outside of tumors, TIMP-1 staining was weak (arrows). Tumors in (A-C) wild-type mice were stained intensely for TIMP-1, whereas tumors in (D-F) PECAM-1-null mice (D-F) were stained much less so. Scale bar, $50 \mu$ m. (G) Results were confirmed by analysis of staining intensity by image analysis. Data are presented as the means \pm standard error; $n=13$. * $P<0.0001$ compared with the wild-type mice.

modulation of the TME, and not through stimulation of angiogenesis (32-35), thus suggesting that PECAM-1 serves two distinct roles in the pathogenesis of cancer.

The present study extended those initial findings by confirming that the presence of functional PECAM-1 on the endothelium promotes a proliferative tumor cell phenotype in vivo, and in tumor cell co-culture assays with ECs or EC surrogates. These pro-proliferative effects were mediated by soluble endothelial-derived factors that are dependent on PECAM-1 homophilic ligand interactions, but are independent of PECAM-1-dependent signaling. These results contrast with previous findings, which indicated that PECAM-1 promotes EC migration via both PECAM-1 homophilic and PECAM-1-dependent, GAG-mediated heterophilic ligand interactions, as well as tyrosine phosphorylation of the cytoplasmic domain and recruitment of the SHP-2 tyrosine phosphatase $(35,52,53)$. Further analyses of the CM from tumor cell/EC co-cultures identified TIMP-1 as a PECAM-1-regulated endothelial factor, the targeting of which in the tumor cell/REN-MP system inhibited tumor cell proliferation. In addition, the finding that TIMP-1 expression may be decreased in metastatic tumors in the lungs of PECAM-1-nulll mice provided evidence of the in vivo significance of the co-culture studies. The potential wider significance of these findings is suggested by the observation that $4 \mathrm{~T} 1$ murine breast cancer cells replicated the in vitro activity of B16-F10 cells. Notably, the pro-proliferative effects of PECAM-1 were associated with discrete phenotypic alterations in B16-F10 tumors; however, the significance of these findings remains to be determined. Taken together, these studies implicated TIMP-1 as a mediator of the growth-promoting effects of PECAM-1 on metastatic tumors through PECAM-1 homophilic interactions. Studies are ongoing to provide in vivo validation of the findings with other models of lung metastasis (e.g. spontaneous lung metastases from 4T1 cancer cells injected into the mammary fat pads of BALB/c mice) (72), as well as with animal models of metastases to other organs, such as the liver (73).

The present study indicated that the stimulatory effects of PECAM-1 on metastatic tumor cell proliferation were dependent on homophilic binding interactions, and were independent of PECAM-1 signaling; these findings may have mechanistic implications for the involvement of PECAM-1 in tumor metastasis. Homophilic interactions enable the localization of PECAM-1 in endothelial intercellular junctions (53), whereas the lack of a requirement of PECAM-1-dependent signaling suggests that PECAM-1 partners with other molecules to trigger the synthesis and/or release of tumor promoting factors, such as TIMP-1. Therefore, these data suggested that junctional PECAM-1, clustered through homophilic interactions, may act as a scaffold or a co-receptor for one or more endothelial surface receptors for tumor-derived factors, which activate the endothelium to secrete TIMP-1 into the TME. The antibody used in the present study (mAb 390) has previously been reported to inhibit EC migration in the setting of angiogenesis through inhibition of PECAM-1-dependent heterophilic adhesion (53). However, the present data suggested that in the context of tumor-endothelial interactions at sites of metastasis, mAb 390 may also have effects on PECAM-1-homophilic binding.

There may also be potential prognostic significance to the finding that PECAM-1-dependent homophilic binding served a role in PECAM-1-mediated tumor cell proliferation. Single nucleotide polymorphisms (SNPs) have been described that code for substitutions in the PECAM-1 molecule at position 125 (leucine to valine) located in domain 1, position 563 (serine to asparagine) in domain 6 , and position 670 
(arginine to glycine) in the cytoplasmic domain (74). These polymorphisms are held in tight genetic linkage, resulting in two major PECAM-1 isoforms within the human population: LSR and VNG, with frequencies of $\sim 0.5$ in the Caucasian population (74). Given the present in vitro findings, which indicated that stimulation of tumor cell proliferation by PECAM-1 may be mediated through PECAM-1-dependent homophilic binding, these SNPs are potentially significant in that they involve sequences of the molecule that either mediate homophilic binding (domain 1) or have regulatory functions on PECAM-1-dependent adhesion (domain 6 and cytoplasmic domain). PECAM-1 gene polymorphisms have been associated with numerous clinical conditions, including sepsis (75), and cardiovascular and cerebrovascular diseases (76-80). Therefore, one or more of the PECAM-1 gene polymorphisms may be associated with reduced TIMP-1 expression, decreased tumor cell proliferation and better clinical outcomes.

The present study implicated TIMP-1, released from the vasculature, as a mediator of the tumor-promoting effects of endothelial PECAM-1, thus suggesting its potential role in the progression of metastatic tumors. This finding is consistent with the results of a previous study, which demonstrated that elevated TIMP-1 expression levels in serum or tissue are associated with poorer outcomes in patients with various malignancies including, lung, gastric and colon cancer (46). Furthermore, the present data are in line with emerging evidence that suggests TIMP-1 is able to promote cell proliferation and survival, including that of tumor cells, independent of MMP inhibition (41-43), via receptor-mediated signaling $(44,45)$. One putative cell surface TIMP-1-binding receptor is CD63 (81), which is a cell surface protein that has been implicated in cancer progression (82-84). Given that the co-culture assay system used in the present study only modeled interactions between tumor cells and the vasculature, the possibility of TIMP-1-mediated effects on other cells in the TME, or on the in vivo activity of MMPs in the ECM or associated with the membrane, cannot be excluded. Future in vivo studies are required to address these issues. Although several candidate PECAM-1-regulated factors were identified from the antibody array conducted in this study, only TIMP-1 was confirmed to be dependent on PECAM-1 by ELISA analysis. The differences in the findings of the antibody array compared with the ELISA are consistent with the variable specificity and sensitivity of a large antibody array, such as the one used in this study; therefore, a confirmatory analysis, such as ELISA, is required (85).

The observation that CM from the tumor/REN-MP, but not tumor/REN co-cultures, stimulated tumor cell proliferation is important in two respects. Firstly, although TIMP-1 is present in the CM from the tumor/REN co-cultures, this CM failed to stimulate the proliferation of cultured tumor cells. This finding suggested that there may be a threshold to the stimulatory effects of TIMP-1 and/or TIMP-1 secreted through PECAM-1-dependent processes may be post-translationally modified to be functionally active in stimulating tumor cell proliferation. Secondly, these data indicated that there is crosstalk between tumor cells and the PECAM-1-expressing cells. While the present study implicated TIMP-1 in PECAM-1-dependent communication between the endothelium and tumor cells, the signals from the tumor cell that are mediated by PECAM-1 remain unknown. One factor being considered is vascular endothelial growth factor (VEGF), as it is highly expressed by melanoma cells (86), PECAM-1 interacts with VEGF receptor on the endothelium (87), and it has been revealed that in B16-F10/REN-MP co-cultures targeting of murine VEGF (and thus VEGF derived from the melanoma cells and not the REN cells) with a murine-specific antibody inhibits PECAM-1-mediated stimulation of tumor cell proliferation (DeLisser, unpublished data). These initial observations suggested that REN cells may exhibit VEGF-binding activity, through which PECAM-1 acts to mediate the release of tumor-promoting soluble factors.

In conclusion, the present study suggested a model to guide future studies of the involvement of PECAM-1 in metastatic tumor progression. It may be hypothesized that PECAM-1, through homophilic interactions, mediates crosstalk between the tumor and the endothelium, participating in the reception/integration of signals from the tumor to the endothelium, which are translated into the release of mediators, such as TIMP-1, that act in a receptor-mediated manner to further stimulate tumor cell proliferation. The potential result is a dynamic, pro-proliferative TME that promotes late metastatic tumor growth and progression, leading to decreased patient survival.

\section{Acknowledgements}

The authors would like to thank Mr. Tony Xia (Temple University, Philadelphia, PA, USA) for his assistance in conducting experiments related to the studies of this paper.

\section{Funding}

The present study was supported by a Merit Award (grant no. BX001203-01) from the Department of Veterans Affairs.

\section{Availability of data and materials}

All data generated or analyzed during this study are included in this published article.

\section{Authors' contributions}

VA performed and analyzed the co-culture studies as well as the in vivo TIMP-1 studies. GC performed the PCNA staining and analyzed the H\&E staining. AP performed the ELISA analyses. FL participated in the co-culture studies. $\mathrm{CH}$ and RD conducted and analyzed the antibody array studies. HD initiated the work, analyzed data and wrote the manuscript. All authors read and approved the final manuscript.

\section{Ethics approval and consent to participate}

The present study was approved by the Institutional Animal Care and Utilization Committee at the University of Pennsylvania School of Medicine (Philadelphia, PA, USA).

\section{Consent for publication}

Not applicable. 


\section{Competing interests}

The authors declare that they have no competing interests.

\section{References}

1. Nguyen DX, Bos PD and Massagué J: Metastasis: From dissemination to organ-specific colonization. Nat Rev Cancer 9: 274-284, 2009.

2. Butler JM, Kobayashi $\mathrm{H}$ and Rafii $\mathrm{S}$ : Instructive role of the vascular niche in promoting tumour growth and tissue repair by angiocrine factors. Nat Rev Cancer 10: 138-146, 2010.

3. Hanahan D and Weinberg RA: Hallmarks of cancer: The next generation. Cell 144: 646-674, 2011.

4. Junttila MR and de Sauvage FJ: Influence of tumour microenvironment heterogeneity on therapeutic response. Nature 501: 346-354, 2013

5. Chen F, Zhuang X, Lin L, Yu P, Wang Y, Shi Y, Hu G and Sun Y: New horizons in tumor microenvironment biology: Challenges and opportunities. BMC Med 13: 45, 2015.

6. Klemm F and Joyce JA: Microenvironmental regulation of therapeutic response in cancer. Trends Cell Biol 25: 198-213, 2015.

7. Fukumura D and Jain RK: Tumor microvasculature and microenvironment: Targets for anti-angiogenesis and normalization. Microvasc Res 74: 72-84, 2007.

8. Valastyan S and Weinberg RA: Tumor metastasis: Molecular insights and evolving paradigms. Cell 147: 275-292, 2011.

9. Ilan N and Madri JA: PECAM-1: Old friend, new partners. Curr Opin Cell Biol 15: 515-524, 2003.

10. Woodfin A, Voisin MB and Nourshargh S: PECAM-1: A multifunctional molecule in inflammation and vascular biology. Arterioscler Thromb Vasc Biol 27: 2514-2523, 2007.

11. Lertkiatmongkol P, Liao D, Mei H, Hu Y and Newman PJ: Endothelial functions of platelet/endothelial cell adhesion molecule-1 (CD31). Curr Opin Hematol 23: 253-259, 2016.

12. Paddock C, Zhou D, Lertkiatmongkol P, Newman PJ and Zhu J: Structural basis for PECAM-1 homophilic binding. Blood 127: 1052-1061, 2016.

13. Newton JP, Buckley CD, Jones EY and Simmons DL: Residues on both faces of the first immunoglobulin fold contribute to homophilic binding sites of PECAM-1/CD31. J Biol Chem 272: 20555-20563, 1997.

14. Nakada MT, Amin K, Christofidou-Solomidou M, O'Brien CD, Sun J, Gurubhagavatula I, Heavner GA, Taylor AH, Paddock C, Sun QH, et al: Antibodies against the first Ig-like domain of human platelet endothelial cell adhesion molecule-1 (PECAM-1) that inhibit PECAM-1-dependent homophilic adhesion block in vivo neutrophil recruitment. J Immunol 164: 452-462, 2000.

15. Coombe DR, Stevenson SM, Kinnear BF, Gandhi NS, Mancera RL, Osmond RI and Kett WC: Platelet endothelia cell adhesion molecule-1 (PECAM-1) and its interactions with glycosaminoglycans: 2. Biochemical analyses. Biochemistry 47: 4863-4875, 2008.

16. Sun J, Williams J, Yan HC, Amin KM, Albelda SM and DeLisser HM: Platelet endothelial cell adhesion molecule-1 (PECAM-1) homophilic adhesion is mediated by immunoglobulin-like domains 1 and 2 and depends on the cytoplasmic domain and the level of surface expression. J Biol Chem 271: 18561-18570, 1996.

17. Sun QH, DeLisser HM, Zukowski MM, Paddock C, Albelda SM and Newman PJ: Individually distinct Ig homology domains in PECAM-1 regulate homophilic binding and modulate receptor affinity. J Biol Chem 271: 11090-11098, 1996.

18. Lee C, Liu A, Miranda-Ribera A, Hyun SW, Lillehoj EP, Cross AS, Passaniti A, Grimm PR, Kim BY, Welling PA, et al: NEU1 sialidase regulates the sialylation state of CD31 and disrupts CD31-driven capillary-like tube formation in human lung microvascular endothelia. J Biol Chem 289: 9121-9135, 2014.

19. Lertkiatmongkol P, Paddock C, Newman DK, Zhu J, Thomas MJ and Newman PJ: The role of sialylated glycans in human platelet endothelial cell adhesion molecule-1 (PECAM-1)-mediated trans homophilic interactions and endothelial cell barrier function. J Biol Chem 291: 26216-26225, 2016.

20. Jackson DE, Kupcho KR and Newman PJ: Characterization of phosphotyrosine binding motifs in the cytoplasmic domain of platelet/endothelial cell adhesion molecule-1 (PECAM-1) that are required for the cellular association and activation of the proteintyrosine phosphatase, SHP-2. J Biol Chem 272: 24868-24875, 1997.
21. Jackson DE, Ward CM, Wang R and Newman PJ: The protein-tyrosine phosphatase SHP-2 binds platelet/endothelial cell adhesion molecule-1 (PECAM-1) and forms a distinct signaling complex during platelet aggregation. Evidence for a mechanistic link between PECAM-1- and integrin-mediated cellular signaling. J Biol Chem 272: 6986-6993, 1997.

22. Cao MY, Huber M, Beauchemin N, Famiglietti J, Albelda SM and Veillette A: Regulation of mouse PECAM-1 tyrosine phosphorylation by the Src and Csk families of protein-tyrosine kinases. J Biol Chem 273: 15765-15772, 1998.

23. Sagawa K, Kimura T, Swieter M and Siraganian RP: The protein-tyrosine phosphatase SHP-2 associates with tyrosinephosphorylated adhesion molecule PECAM-1 (CD31). J Biol Chem 272: 31086-31091, 1997.

24. Pumphrey NJ, Taylor V, Freeman S, Douglas MR, Bradfield PF Young SP, Lord JM, Wakelam MJ, Bird IN, Salmon M, et al: Differential association of cytoplasmic signalling molecules SHP-1, SHP-2, SHIP and phospholipase C-gamma1 with PECAM-1/CD31. FEBS Lett 450: 77-83, 1999.

25. Vaporciyan AA, DeLisser HM, Yan HC, Mendiguren II, Thom SR, Jones ML, Ward PA and Albelda SM: Involvement of platelet-endothelial cell adhesion molecule-1 in neutrophil recruitment in vivo. Science 262: 1580-1582, 1993.

26. Thompson RD, Wakelin MW, Larbi KY, Dewar A, Asimakopoulos G, Horton MA, Nakada MT and Nourshargh S: Divergent effects of platelet-endothelial cell adhesion molecule-1 and beta 3 integrin blockade on leukocyte transmigration in vivo. J Immunol 165: 426-434, 2000.

27. Woodfin A, Reichel CA, Khandoga A, Corada M, Voisin MB, Scheiermann C, Haskard DO, Dejana E, Krombach F and Nourshargh S: JAM-A mediates neutrophil transmigration in a stimulus-specific manner in vivo: Evidence for sequential roles for JAM-A and PECAM-1 in neutrophil transmigration. Blood 110: 1848-1856, 2007.

28. Newton-Nash DK and Newman PJ: A new role for platelet-endothelial cell adhesion molecule-1 (CD31): Inhibition of TCR-mediated signal transduction. J Immunol 163: 682-688, 1999.

29. Prager E, Staffler G, Majdic O, Säemann M, Godár S, Zlabinger G and Stockinger $\mathrm{H}$ : Induction of hyporesponsiveness and impaired T lymphocyte activation by the CD31 receptor:ligand pathway in T cells. J Immunol 166: 2364-2371, 2001.

30. Rosenblum WI, Murata S, Nelson GH, Werner PK, Ranken R and Harmon RC: Anti-CD31 delays platelet adhesion/aggregation at sites of endothelial injury in mouse cerebral arterioles. Am J Pathol 145: 33-36, 1994.

31. Patil S, Newman DK and Newman PJ: Platelet endothelial cell adhesion molecule-1 serves as an inhibitory receptor that modulates platelet responses to collagen. Blood 97: 1727-1732, 2001.

32. DeLisser HM, Christofidou-Solomidou M, Strieter RM, Burdick MD, Robinson CS, Wexler RS, Kerr JS, Garlanda C, Merwin JR, Madri JA, et al: Involvement of endothelial PECAM-1/ CD31 in angiogenesis. Am J Pathol 151: 671-677, 1997.

33. Zhou Z, Christofidou-Solomidou M, Garlanda C and DeLisser HM: Antibody against murine PECAM-1 inhibits tumor angiogenesis in mice. Angiogenesis 3: 181-188, 1999.

34. Cao G, O'Brien CD, Zhou Z, Sanders SM, Greenbaum JN, Makrigiannakis A and DeLisser HM: Involvement of human PECAM-1 in angiogenesis and in vitro endothelial cell migration. Am J Physiol Cell Physiol 282: C1181-C1190, 2002.

35. Cao G, Fehrenbach ML, Williams JT, Finklestein JM, Zhu JX and Delisser HM: Angiogenesis in platelet endothelial cell adhesion molecule-1-null mice. Am J Pathol 175: 903-915, 2009.

36. Carrithers M, Tandon S, Canosa S, Michaud M, Graesser D and Madri JA: Enhanced susceptibility to endotoxic shock and impaired STAT3 signaling in CD31-deficient mice. Am J Pathol 166: 185-196, 2005.

37. Maas M, Stapleton M, Bergom C, Mattson DL, Newman DK and Newman PJ: Endothelial cell PECAM-1 confers protection against endotoxic shock. Am J Physiol Heart Circ Physiol 288: H159-H164, 2005.

38. DeLisser H, Liu Y, Desprez PY, Thor A, Briasouli P, Handumrongkul C, Wilfong J, Yount G, Nosrati M, Fong S, et al: Vascular endothelial cell adhesion molecule 1 (PECAM-1) regulates advanced metastatic progression. Proc Natl Acad Sci USA 107: 18616-18621, 2010.

39. Clark IM, Swingler TE, Sampieri CL and Edwards DR: The regulation of matrix metalloproteinases and their inhibitors. Int $\mathrm{J}$ Biochem Cell Biol 40: 1362-1378, 2008 
40. Brew K and Nagase $\mathrm{H}$ : The tissue inhibitors of metalloproteinases (TIMPs): An ancient family with structural and functional diversity. Biochim Biophys Acta 1803: 55-71, 2010.

41. Chesler L, Golde DW, Bersch N and Johnson MD: Metalloproteinase inhibition and erythroid potentiation are independent activities of tissue inhibitor of metalloproteinases-1. Blood 86 : 4506-4515, 1995.

42. Liu XW, Taube ME, Jung KK, Dong Z, Lee YJ, Roshy S, Sloane BF, Fridman R and Kim HR: Tissue inhibitor of metalloproteinase-1 protects human breast epithelial cells from extrinsic cell death: A potential oncogenic activity of tissue inhibitor of metalloproteinase-1. Cancer Res 65: 898-906, 2005.

43. Toricelli M, Melo FH, Peres GB, Silva DC and Jasiulionis MG: Timp1 interacts with beta-1 integrin and CD63 along melanoma genesis and confers anoikis resistance by activating PI3-K signaling pathway independently of Akt phosphorylation. Mol Cancer 12: 22, 2013

44. Chirco R, Liu XW, Jung KK and Kim HR: Novel functions of TIMPs in cell signaling. Cancer Metastasis Rev 25: 99-113, 2006.

45. Stetler-Stevenson WG: Tissue inhibitors of metalloproteinases in cell signaling: Metalloproteinase-independent biological activities. Sci Signal 1: re6, 2008.

46. Aljada IS, Ramnath N, Donohue K, Harvey S, Brooks JJ, Wiseman SM, Khoury T, Loewen G, Slocum HK, Anderson TM, et al: Upregulation of the tissue inhibitor of metalloproteinase-1 protein is associated with progression of human non-small-cell lung cancer. J Clin Oncol 22: 3218-3229, 2004.

47. Pesta M, Kulda V, Kucera R, Pesek M, Vrzalova J, Liska V, Pecen L, Treska V, Safranek J, Prazakova M, et al: Prognostic significance of TIMP-1 in non-small cell lung cancer. Anticancer Res 31: 4031-4038, 2011.

48. Grunnet M, Mau-Sørensen M and Brünner N: Tissue inhibitor of metalloproteinase 1 (TIMP-1) as a biomarker in gastric cancer: A review. Scand J Gastroenterol 48: 899-905, 2013.

49. Cui H, Seubert B, Stahl E, Dietz H, Reuning U, Moreno-Leon L, Ilie M, Hofman P, Nagase H, Mari B, et al: Tissue inhibitor of metalloproteinases-1 induces a pro-tumourigenic increase of miR-210 in lung adenocarcinoma cells and their exosomes. Oncogene 34: 3640-3650, 2015.

50. Song G, Xu S, Zhang H, Wang Y, Xiao C, Jiang T, Wu L, Zhang T, Sun X, Zhong L, et al: TIMP1 is a prognostic marker for the progression and metastasis of colon cancer throughFAK-PI3K/AKT and MAPK pathway. J Exp Clin Cancer Res 35: 148, 2016.

51. Smythe WR, Hwang HC, Amin KM, Eck SL, Davidson BL, Wilson JM, Kaiser LR and Albelda SM: Use of recombinant adenovirus to transfer the herpes simplex virus thymidine kinase (HSVtk) gene to thoracic neoplasms: An effective in vitro drug sensitization system. Cancer Res 54: 2055-2059, 1994

52. Zhu JX, Cao G, Williams JT and Delisser HM: SHP-2 phosphatase activity is required for PECAM-1-dependent cell motility. Am J Physiol Cell Physiol 299: C854-C865, 2010.

53. Abraham V, Parambath A, Joe DS and DeLisser HM: Influence of PECAM-1 ligand interactions on PECAM-1-dependent cell motility and filopodia extension. Physiol Rep 4: e13030, 2016.

54. Fehrenbach ML, Cao G, Williams JT, Finklestein JM and Delisser HM: Isolation of murine lung endothelial cells. Am J Physiol Lung Cell Mol Physiol 296: L1096-L1103, 2009.

55. Duncan GS, Andrew DP, Takimoto H, Kaufman SA, Yoshida H, Spellberg J, de la Pompa JL, Elia A, Wakeham A, Karan-Tamir B et al: Genetic evidence for functional redundancy of Platelet/ Endothelial cell adhesion molecule-1 (PECAM-1): CD31-deficient mice reveal PECAM-1-dependent and PECAM-1-independent functions. J Immunol 162: 3022-3030, 1999.

56. Fowlkes JL, Serra DM, Bunn RC, Thrailkill KM, Enghild JJ and Nagase H: Regulation of insulin-like growth factor (IGF)-I action by matrix metalloproteinase-3 involves selective disruption of IGF-I/IGF-binding protein-3 complexes. Endocrinology 145 620-626, 2004

57. Wang P, Henning SM and Heber D: Limitations of MTT and MTS-based assays for measurement of antiproliferative activity of green tea polyphenols. PLoS One 5: e10202, 2010.

58. Lovelock JD, Baker AH, Gao F, Dong JF, Bergeron AL, McPheat W, Sivasubramanian N and Mann DL: Heterogeneous effects of tissue inhibitors of matrix metalloproteinases on cardiac fibroblasts. Am J Physiol Heart Circ Physiol 288: H461-H468, 2005.

59. Kalra J, Dragowska WH and Bally MB: Using pharmacokinetic profiles and digital quantification of stained tissue microarrays as a medium-throughput, quantitative method for measuring the kinetics of early signaling changes following integrin-linked kinase inhibition in an in vivo model of cancer. J Histochem Cytochem 63: 691-709, 2015
60. Dunleavey JM, Xiao L, Thompson J, Kim MM, Shields JM, Shelton SE, Irvin DM, Brings VE, Ollila DW, Brekken RA, et al: Vascular channels formed by subpopulations of PECAM1 ${ }^{+}$ melanoma cells. Nat Commun 5: 5200, 2014.

61. Chacko AM, Nayak M, Greineder CF, Delisser HM and Muzykantov VR: Collaborative enhancement of antibody binding to distinct PECAM-1 epitopes modulates endothelial targeting. PLoS One 7: e34958, 2012.

62. Siemianowicz K, Likus W, Francuz T and Garczorz W: Effect of elastin-derived peptides on the production of tissue inhibitor of metalloproteinase-1, -2 , and -3 and the ratios in various endothelial cell lines. Exp Ther Med 9: 2245-2250, 2015.

63. Kim HI, Lee HS, Kim TH, Lee JS, Lee ST and Lee SJ: Growth-stimulatory activity of TIMP-2 is mediated through c-Src activation followed by activation of FAK, PI3-kinase/AKT, and ERK1/2 independent of MMP inhibition in lung adenocarcinoma cells. Oncotarget 6: 42905-42922, 2015.

64. Ernst M and Putoczki TL: Molecular pathways: IL11 as a tumorpromoting cytokine-translational implications for cancers. Clin Cancer Res 20: 5579-5588, 2014.

65. Johnstone CN, Chand A, Putoczki TL and Ernst M: Emerging roles for IL-11 signaling in cancer development and progression: Focus on breast cancer. Cytokine Growth Factor Rev 26: 489-498, 2015.

66. Karmann K, Hughes CC, Schechner J, Fanslow WC and Pober JS: CD40 on human endothelial cells: Inducibility by cytokines and functional regulation of adhesion molecule expression. Proc Natl Acad Sci USA 92: 4342-4346, 1995.

67. Korniluk A, Kemona H and Dymicka-Piekarska V: Multifunctional CD40L: Pro- and anti-neoplastic activity. Tumour Biol 35: 9447-9457, 2014.

68. Geng L, Cuneo KC, Cooper MK, Wang H, Sekhar K, Fu A and Hallahan DE: Hedgehog signaling in the murine melanoma microenvironment. Angiogenesis 10: 259-267, 2007.

69. Rimkus TK, Carpenter RL, Qasem S, Chan M and Lo HW: Targeting the sonic hedgehog signaling pathway: Review of smoothened and GLI inhibitors. Cancers (Basel) 8: E22, 2016.

70. Velasco-Velázquez M, Jiao X, De La Fuente M, Pestell TG, Ertel A, Lisanti MP and Pestell RG: CCR5 antagonist blocks metastasis of basal breast cancer cells. Cancer Res 72: 3839-3850, 2012.

71. Sasaki S, Baba T, Nishimura T, Hayakawa Y, Hashimoto S, Gotoh $\mathrm{N}$ and Mukaida N: Essential roles of the interaction between cancer cell-derived chemokine, CCL4, and intra-bone CCR5-expressing fibroblasts in breast cancer bone metastasis. Cancer Lett 378: 23-32, 2016

72. Fantozzi A and Christofori G: Mouse models of breast cancer metastasis. Breast Cancer Res 8: 212, 2006

73. de Jong GM, Aarts F, Hendriks T, Boerman OC and Bleichrodt RP: Animal models for liver metastases of colorectal cancer: Research review of preclinical studies in rodents. J Surg Res 154: 167-176, 2009.

74. Novinska MS, Pietz BC, Ellis TM, Newman DK and Newman PJ: The alleles of PECAM-1. Gene 376: 95-101, 2006.

75. Sun W, Li FS, Zhang YH, Wang XP and Wang CR: Association of susceptibility to septic shock with platelet endothelial cell adhesion molecule-1 gene Leu125Val polymorphism and serum sPECAM-1 levels in sepsis patients. Int J Clin Exp Med 8: 20490-20498, 2015.

76. Elrayess MA, Webb KE, Flavell DM, Syvänne M, Taskinen MR, Frick MH, Nieminen MS, Kesäniemi YA, Pasternack A, Jukema JW, et al: A novel functional polymorphism in the PECAM-1 gene $(53 \mathrm{G}>\mathrm{A})$ is associated with progression of atherosclerosis in the LOCAT and REGRESS studies. Atherosclerosis 168: 131-138, 2003.

77. Elrayess MA, Webb KE, Bellingan GJ, Whittall RA, Kabir J, Hawe E, Syvänne M, Taskinen MR, Frick MH, et al: R643G polymorphism in PECAM-1 influences transendothelial migration of monocytes and is associated with progression of CHD and CHD events. Atherosclerosis 177: 127-135, 2004.

78. Wei YS, Lan Y, Liu YG, Meng LQ, Xu QQ and Xie HY: Platelet-endothelial cell adhesion molecule-1 gene polymorphism and its soluble level are associated with ischemic stroke. DNA Cell Biol 28: 151-158, 2009.

79. Sahebkar A, Morris DR, Biros E and Golledge J: Association of single nucleotide polymorphisms in the gene encoding platelet endothelial cell adhesion molecule- 1 with the risk of myocardial infarction: A systematic review and meta-analysis. Thromb Res 132: 227-233, 2013. 
80. Song Y, Zhao R, Long L, Zhang N and Liu Y: Leu125Va polymorphism of platelet endothelial cell adhesion molecule-1 is associated with atherosclerotic cerebral infarction in Chinese Han population. Int J Clin Exp Med 7: 5808-5813, 2014.

81. Jung KK, Liu XW, Chirco R, Fridman R and Kim HR: Identification of CD63 as a tissue inhibitor of metalloproteinase-1 interacting cell surface protein. EMBO J 25: 3934-3942, 2006.

82. Radford KJ, Thorne RF and Hersey P: Regulation of tumor cell motility and migration by CD63 in a human melanoma cell line. J Immunol 158: 3353-3358, 1997.

83. Iida J, Skubitz AP, McCarthy JB and Skubitz KM: Protein kinase activity is associated with CD63 in melanoma cells. J Trans Med 3: 42, 2005.

84. Seubert B, Cui H, Simonavicius N, Honert K, Schäfer S, Reuning U, Heikenwalder M, Mari B and Krüger A: Tetraspanin CD63 acts as a pro-metastatic factor via $\beta$-catenin stabilization. Int J Cancer 136: 2304-2315, 2015.

85. Huang Y and Zhu H: Protein array-based approaches for biomarker discovery in cancer. Genomics Proteomics Bioinformatics 15: 73-81, 2017.
86. Spinella F, Caprara V, Cianfrocca R, Rosanò L, Di Castro V, Garrafa E, Natali PG and Bagnato A: The interplay between hypoxia, endothelial and melanoma cells regulates vascularization and cell motility through endothelin-1 and vascular endothelial growth factor. Carcinogenesis 35: 840-848, 2014.

87. Tzima E, Irani-Tehrani M, Kiosses WB, Dejana E, Schultz DA, Engelhardt B, Cao G, DeLisser H and Schwartz MA: A mechanosensory complex that mediates the endothelial cell response to fluid shear stress. Nature 437: 426-431, 2005.

This work is licensed under a Creative Commons Attribution-NonCommercial-NoDerivatives 4.0 International (CC BY-NC-ND 4.0) License. 